\title{
Análise petrográfica e proveniência do Arenito Pedreira, Jurássico Superior da Bacia do Paraná, sul do Brasil
}

\author{
Matheus P. BRÜCKMANN'', Ruy Paulo PHILIPP², Claiton Marlon dos Santos SCHERER², \\ Eduardo ESPÍNDOLA \& Leonardo HALFEN³
}

\begin{abstract}
1 Programa de Pós-graduação em Geociências, Universidade Federal do Rio Grande do Sul. Av. Bento Gonçalves, 9.500, CEP 91.540-000, Porto Alegre, RS, Brasil (matheusbruck@gmail.com, eduardo. espindola@ufrgs.br).

2 Instituto de Geociências, Universidade Federal do Rio Grande do Sul. Av. Bento Gonçalves, 9.500, CEP 91.540-000, Porto Alegre, RS, Brasil (ruy.philipp@ufrgs.br, claiton.scherer@ufrgs.br).

${ }^{3}$ Instituto de Geociências, Universidade Federal do Rio Grande do Sul. Av. Bento Gonçalves, 9.500, CEP 91.540-000, Porto Alegre, RS, Brasil (leonardohalfen@gmail.com).
\end{abstract}

\begin{abstract}
Resumo. Na região sudeste da Bacia do Paraná, ocorre uma unidade informalmente denominada de Arenito Pedreira. Para definir as relações estratigráficas e caracterizar esta unidade foram avaliados dois furos de sondagem e selecionadas amostras representativas para análise petrográfica e contagem modal dos constituintes para definição da proveniência. O Arenito Pedreira está depositado entre a Formação Botucatu, por desconformidade sobreposta, e a Formação Rio do Rastro, com a qual tem contato erosivo. A unidade écomposta por uma sucessão de ciclos granodecrescentes constituídos por arenitos conglomeráticos, conglomerados arenosos, arenitos com estratificação cruzada tangencial e cruzada de baixo ângulo, arenitos com marcas de ondas e pelitos laminados, respectivamente. Os arenitos são classificados como arcóseos líticos e arcóseos, tem seleção média, elevados em grãos de feldspatos e quartzo. As feições diagenéticas caracterizam condições de eodiagênese e mesodiagênese, com feições de ambientes de clima continental seco. A análise da proveniência aponta para fontes associadas a arco magmático dissecado. Os litoclastos descritos são semelhantes às rochas encontradas nas unidades do Cinturão Dom Feliciano situadas mais ao sul, no terreno Tijucas e no Batólito Pelotas. Estas informações sugerem uma área fonte próxima e permitem admitir que o soerguimento do Arco de Rio Grande de direção NW-SE, seja responsável pelo fornecimento de sedimentos para a constituição do Arenito Pedreira.
\end{abstract}

Palavras-chave. Petrografia, proveniência, Arenito Pedreira, Bacia do Paraná, Jurássico Superior.

Abstract. Petrographic analysis and provenance of Pedreira Sandstone, Neojurassic OF THE PARANÁ BASIN, SOUTHERN BRAZIL. In the south-west portion of the Paraná Basin, there is a unit informally called Pedreira Sandstone. In order to define the stratigraphic relations and to characterize this unit, two boreholes were evaluated and representative samples were selected for petrographic analysis and modal counting of the constituents in order to define its provenance. The Pedreira Sandstone was deposited between the Botucatu Formation by overlapped unconformity and the Rio do Rastro Formation, with which it has erosive contact. It is composed of a succession of fining-upward cycles consisting of conglomerate sandstones, sandy conglomerates sandstone packages with tangential cross-bedding and low angle crossbedding, sandstones with ripple marks and laminated pelites respectively. The sandstones are classified as lithic arkoses and arkoses, have a medium selection, with a high ratio of feldspar and quartz grains. The diagenetic features characterize eodiagenesis and mesodiagenesis conditions, with dry continental climate features. The provenance analysis points to sources associated with a dissected magmatic arc and the lithoclasts described are similar to the rocks found in the Dom Feliciano Belt located further south on the Tijucas terranes and Pelotas Batholith. These data suggest a source area near the deposition area and allows accepting that the NW-SE direction uplift of the Rio Grande Arc is responsible for the provision of sediments for the formation of the Pedreira Sandstone.

Keywords. Petrography, provenance, Pedreira Sandstone, Paraná Basin, Upper Jurassic. 


\section{Introdução}

O estudo petrográfico associado à estratigrafia em bacias sedimentares permite classificar as litologias e avaliar os processos diagenéticos. A integração dos dados de campo com estas informações possibilita definir o ambiente e as condições de deposição, avaliar os processos de litificação envolvidos e as áreas fontes dos sedimentos. Desta forma, a petrografia auxilia no entendimento da evolução e na correlação de unidades estratigráficas.

O registro do Triássico na Bacia do Paraná está especialmente preservado no estado do Rio Grande do Sul. Este período está caracterizado pelo fim da sedimentação eólica da Formação Pirambóia e pela deposição do Grupo Rosário do Sul, com as formações Sanga do Cabral (Triássico Inferior) e Santa Maria (Triássico Médio a Superior) (Andreis et al., 1980).

O intervalo entre o Jurássico Superior e o Cretáceo Inferior é caracterizado pelas rochas sedimentares das formações Guará e Botucatu, do Grupo São Bento, recobertas por rochas vulcânicas do Grupo Serra Geral, este último associado aos processos de abertura do Oceano Atlântico. No entanto, uma unidade distinta, depositada provavelmente entre o Triássico Médio e o Jurássico, denominada informalmente de Arenito Pedreira, foi descrita nos municípios de São Leopoldo e Sapucaia do Sul (Nowatzki \& Kern, 2000; Nowatzki \& Klein, 2001). A porção inferior da sucessão do Arenito Pedreira está sobreposta através de um contato erosivo com os arenitos do topo da Formação Rio do Rastro. O limite superior está marcado pela transição para a Formação Botucatu através de uma desconformidade (Nowatzki \& Klein, 2001). O Arenito Pedreira é composto por uma sucessão de ciclos granodecrescentes constituídos por arenitos conglomeráticos e conglomerados arenosos clasto-suportados e polimíticos, arenitos com marcas de ondas e pelitos laminados para o topo (Espíndola, 2017).

Para caracterizar o Arenito Pedreira, foi realizada uma análise estratigráfica e petrográfica de dois furos de sondagem, com seleção de sete amostras representativas para confecção de lâminas delgadas. O objetivo deste trabalho é avaliar, através da análise petrográfica, as fontes dos sedimentos e as condições diagenéticas atuantes durante a litificação. Os resultados obtidos são utilizados juntamente com as informações da literatura para caracterizar os processos tectônicos envolvidos durante a sedimentação do Arenito Pedreira e auxiliar na interpretação da evolução da borda sudeste da Bacia do Paraná.

\section{2 Área, materiais e métodos}

\section{1 Contexto tectônico}

A estratigrafia da porção sul da BP no estado do Rio Grande do Sul registra uma sucessão de rochas sedimentares depositadas entre o Carbonífero Superior ao Cretáceo (Milani et al., 2007; Holz et al., 2010) (Fig. 1). O embasamento da BP é caracterizado por núcleos continentais antigos, representados por fragmentos de áreas cratônicas do Arqueano e do Paleoproterozoico, envoltos por cinturões orogênicos neoproterozoicos associados com o ciclo orogênico Brasiliano (900-540 Ma). O Escudo Sul-rio-grandense (ESRG) é constituído por exposições descontínuas do Terreno Taquarembó a sudoeste, representando a borda retrabalhada do Cráton Rio de La Plata (CRLP), envolto ao leste pelos terrenos São Gabriel e Tijucas e pelo Batólito Pelotas, unidades do Cinturão Dom Feliciano.

\subsection{Geologia do Arenito Pedreira}

O Arenito Pedreira foi descrito originalmente nos municípios de Sapucaia do Sul e São Leopoldo (Nowatzki \& Kern, 2000; Nowatzki \& Klein, 2001) (Fig. 2) e, neste trabalho em furos de sondagens localizados na região de Osório. Na primeira área, a porção inferior da sucessão do Arenito Pedreira está sobreposta aos arenitos do topo da Formação Sanga do Cabral através de um contato erosivo. O limite superior está marcado pela transição para a Formação Botucatu através de uma desconformidade, em resposta às movimentações tectônicas que ocasionaram a erosão de unidades sotopostas e exposição do embasamento (Nowatzki \& Klein, 


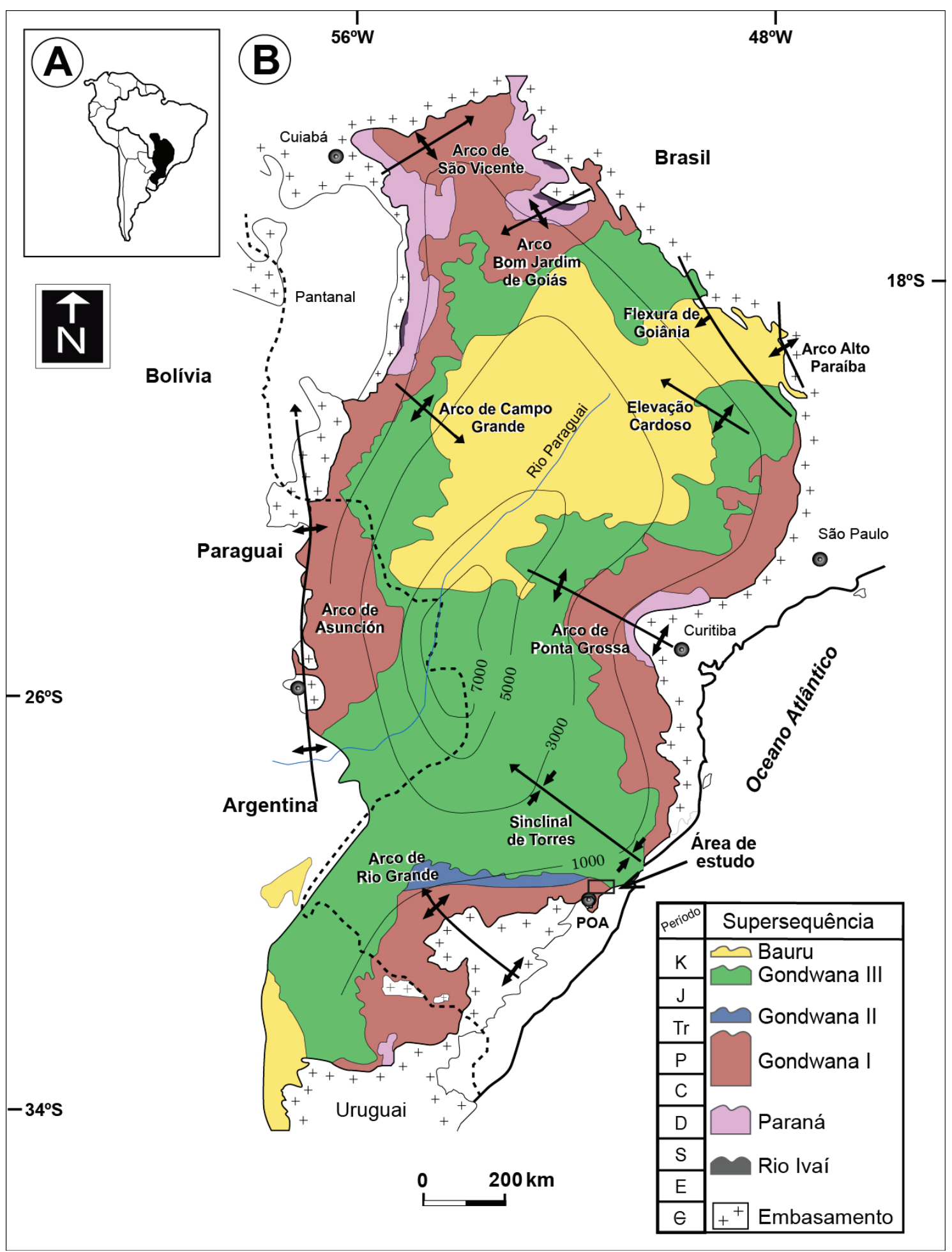

Figura 1. Área de exposição da BP no Brasil; B) Mapa geológico simplificado da BP destacando as seis Supersequências propostas por Milani (1997) e os limites do embasamento. Também são apresentados o contorno estrutural (profundidade) do embasamento cristalino e as principais estruturas tectônicas da bacia. A localização dos furos de sondagem analisados é marcada por um retângulo preto.

Figure 1. Exposure area of the Paraná Basin in Brazil; B) Simplified geologic map of the Paraná Basin highlighting the six Supersequences proposed by Milani (1997) and the limits of the basement. Also presented the main structures of the basin and the structural contour (depth) of the crystalline basement. The location of the study area is marked by a black rectangle. 
2001). Nos furos de sondagem, a sucessão observada está depositada entre a Formação Botucatu, por desconformidade sobreposta, e a Formação Rio do Rastro, com a qual tem contato erosivo (Espíndola, 2017). A espessura desta sucessão no furo TG-98 é de 25 m (cotas: -410 e -435 m), e no furo TG-100, de 29 m (cotas: -391 e $-420 \mathrm{~m})$.
O Arenito Pedreira recebeu este nome devido a uma sessão estratigráfica levantada no município de Sapucaia do Sul, RS e na região de São Leopoldo, cidade vizinha, descrito por Nowatzki \& Kern (2000) como uma sucessão eólica com dunas e interdunas depositadas sobre a Formação Sanga do Cabral e abaixo da Formação Botucatu em ambas

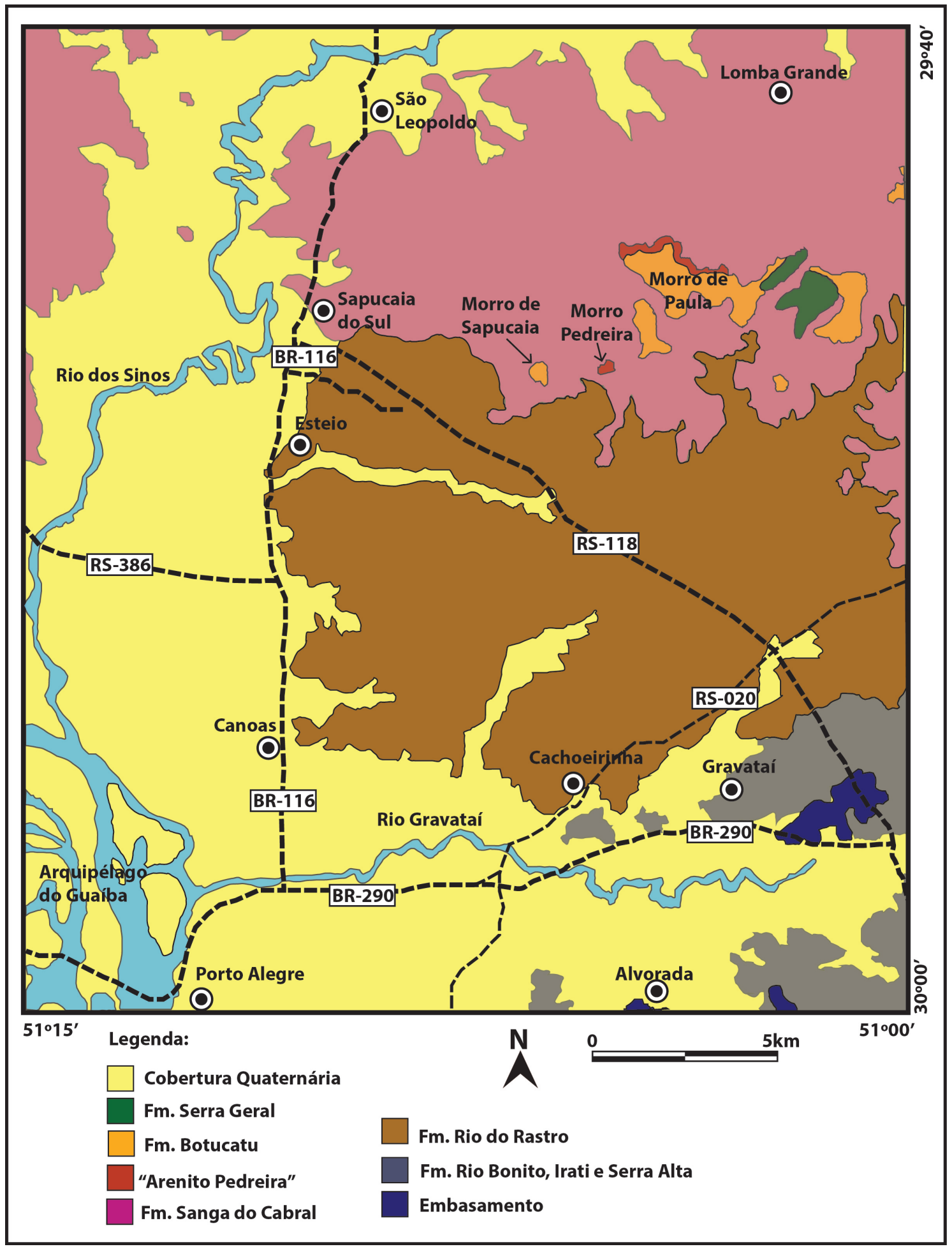

Figura 2. Mapa geológico da porção norte da região metropolitana de Porto Alegre, destacando as ocorrências do Arenito Pedreira nos morros da Pedreira e de Paula (modificado de Nowatzki \& Kern, 2000).

Figure 2. Simplified geological map of the north portion of metropolitan region of Porto Alegre, highlighting the occurrences of the Pedreira Arenite in Pedreira and de Paula hills (modified from Nowatzki \& Kern, (2000). 
por desconformidade. A mineralogia descrita apresenta 95\% de quartzo mono e policristalino com $1 \%$ de feldspatos totalmente caolinizados, litoclastos de pelito, quartzito, arenito fino, rochas ígneas e minerais acessórios de muscovita, epidoto, alanita apatita e piroxênios.

Nowatzki \& Klein (2001) descrevem o Arenito Pedreira como depósitos de leques aluviais na base, fluviais entrelaçados na sua porção intermediária e de dunas e interdunas eólicas, na parte superior. Em uma análise faciológica detalhada, aqueles autores descrevem brechas com gradação inversa, arenitos com estratificações cruzadas tangencial de pequeno porte, arenitos com estratificações cruzadas planar de pequeno porte, arenitos com marcas de ondas, arenitos maciços, arenitos com estratificações cruzadas de médio ou grande porte e arenitos com laminações cruzadas tangenciais. Os arenitos fluviais são litarenitos conglomeráticos e os litoclastos presentes podem chegar a 30\%. Estes são mal selecionados, subangulosos, constituídos por quartzo monocristalino, ortoclásio, feldspato pertítico, microclínio, litoclastos sedimentares (argilito, siltito, arenito fino e chert), litoclastos de metamórficas de baixo grau (filito), litoclastos plutônicos (granitos) e biotitas. Apresentam também cimentação carbonática em algumas porções.

No furo de sondagem TG-98 observa-se três ciclos de deposição de ruditos, intercalados com arenitos e pelitos no topo. A sucessão inicia com uma base erosiva marcada por arenitos contendo grânulos e intraclastos na base da estratificação cruzada. Este pacote grada para uma sucessão granodecrescente de cerca de 10 $m$ de espessura, contendo na base conglomerado arenoso clasto suportado com predomínio e seixos de até $5 \mathrm{~cm}$ de variadas litologias, diminuindo a quantidade para o topo. Sucedido por arenito médio a grosso, com grânulos e seixos dispersos. Na sequência, arenito médio a fino com estratificação cruzada de baixo ângulo e dois níveis de seixos com ação microbiana entre eles. No topo ocorrem arenitos com ripples e estratificações cruzadas. Acima deste pacote ocorre uma sequência com arenito médio com intraclastos de até $4 \mathrm{~cm}$, sucedidos por arenito grosso a muito grosso com estratificação cruzada de baixo ângulo na base e cruzada tangencial no topo. Sucessivamente ocorre um pacote de arenito fino com ripples coberto por pelito laminado no topo. Sobreposto ocorre um novo pacote de arenito conglomerático gradando para conglomerado clasto-suportado com arcabouço arenoso, contendo clastos de litologias e tamanhos variados de até $7 \mathrm{~cm}$. Intraclastos nos últimos dois metros, com dois ciclos granodecrescentes até areia grossa com estratificação cruzada tangencial e estratificação cruzada de baixo ângulo.

No furo de sondagem TG-100 foram descritos dois ciclos principais de depósitos rudíticos. Entretanto, a sedimentação começa na base com um arenito fino com laminações cruzadas de marcas de ondas e três lentes de pelitos micáceos, gretados e com estruturas de carga, seguido por dois ciclos de arenito fino com laminações cruzadas de marcas onduladas gradando para pelito bioturbado e gretado. Seguem ciclos de 5 a $17 \mathrm{~cm}$ de arenitos com estratificação cruzada de baixo ângulo e grânulos dispersos na base. A sucessão segue com conglomerado clasto suportado com base erosiva e tamanho de grãos até seixo, com clastos subarredondados e de baixa esfericidade. Em seguida conglomerado clasto suportado polimítico, com ciclos de até $30 \mathrm{~cm}$ gradando para arenito conglomerático, sucedidos por conglomerado clasto suportado com gradação normal até arenito muito fino micáceo. Clastos de até $4 \mathrm{~cm}$ de quartzo. Sobreposto por conglomerado polimítico e clasto suportado com grande variação granulométrica, com seixos e intraclastos argilosos de até 1 $\mathrm{cm}$. No topo ocorrem ciclos fining upward, com conglomerados polimíticos clasto suportados gradando para arenito médio grosso com estratificação cruzada de baixo ângulo. Clastos e intraclastos argilosos de até $2 \mathrm{~cm}$ dispersos. Após $2 \mathrm{~m}$ de horizonte encoberto, ocorrem um arenito maciço com lag de $4 \mathrm{~cm}$ na porção central, seguido de arenito com estratificação cruzada tangencial, gradando de arenito grosso na base para arenito médio a grosso em direção ao topo e estratificação cruzada de baixo ângulo e laminações cruzadas de marcas onduladas. 
Sequencialmente ocorre meio metro de pelito maciço avermelhado seguido de $1 \mathrm{~m}$ de arenito fino bioturbado. Este pacote é sucedido por um nível de $2 \mathrm{~m}$ de espessura de conglomerados arenosos a arenito conglomeráticos, clasto suportado e polimítico, com estratificação cruzada de baixo ângulo. Na porção central, arenito mais grosso com intraclastos argilosos e seixos de até $2 \mathrm{~cm}$. Acima, ocorrem $3 \mathrm{~m}$ de arenito fino a médio com estratificação cruzada de baixo ângulo e nível micáceo, seguido de $2 \mathrm{~m}$ de arenito fino maciço fluidizado no topo. Esta sucessão prossegue com um pacote de um arenito fino a médio com estratificação cruzada de baixo ângulo e laminações cruzadas de marcas de onda no topo, seguido por $1 \mathrm{~m}$ de pelito maciço vermelho. Este ciclo é sucedido por uma nova deposição de conglomerados clasto suportado, polimítico com predomínio de seixos subarredondados de até $5 \mathrm{~cm}$ horizontalizados, com arenito grosso no topo. A sucessão prossegue com $3 \mathrm{~m}$ de arenito fıno a médio com estratifıcação cruzada de baixo ângulo e intraclastos, finalizando com um pacote de quatro ciclos de 20 a $30 \mathrm{~cm}$ de conglomerado arenoso na base gradando para arenito médio por vezes maciço ou com estratificação cruzada de baixo ângulo.

Os níveis de conglomerados e arenitos conglomeráticos contêm clastos e seixos com grande diversidade composicional, formas e tamanhos. Foram identificados litoclastos de dez litologias distintas, distribuídas entre silimanitagranada-biotita gnaisses, gnaisses tonalíticos a monzograníticos e metagranitos miloníticos de fácies anfibolito, rochas metassedimentares de baixo grau (metapsamitos, quartzitos e xistos), muscovita granitos miloníticos, sienogranitos indeformados, arenitos arcoseanos, andesitos e basaltos porfiríticos. Os clastos e seixos observados no furo TG-98 apresentam formas variadas com baixa esfericidade e moderada angulosidade. $\mathrm{Na}$ base deste furo, os litoclastos são menores, com predominância de grânulos subarredondados com baixa esfericidade e seixos subarredondados dispersos. No furo TG-100, os litoclastos analisados apresentam um aumento no tamanho do topo para a base do furo. Os litoclastos se apresentam na forma de grânulos em sua maioria, com formas subarredondadas a subangulosas, moderada esfericidade e aparecem disseminados. $\mathrm{Na}$ amostra $\mathrm{Pl}-3$ há um aumento relevante na proporção de grânulos, estes com um baixo arredondamento e esfericidade. Os conglomerados da porção mais basal, entretanto, apresentam grande proporção de intraclastos lamosos e vulcânicos com baixa esfericidade e tamanhos de até $2 \mathrm{~cm}$.

\subsection{Materiais e métodos}

Para este estudo foram descritos e amostrados os furos de sondagem TG-98 e TG100, obtidos em campanha de pesquisa para carvão pela CPRM. Estes furos estão situados a cerca de oito quilômetros ao leste da cidade de Osório, respectivamente, nas coordenadas $29^{\circ} 54^{\prime} 06^{\prime \prime}$ (S) e 50 09'37" (W) e, 2952'30" (S) e $50^{\circ} 11^{\prime} 39^{\prime \prime}$ (W) (Fig. 3).

A análise dos furos de sondagem envolveu a descrição dos tipos litológicos e das estruturas sedimentares, com descrição petrográfica macroscópica dos clastos e seixos encontrados nos níveis de conglomerados e arenitos conglomeráticos. A análise petrográfica foi realizada com base em sete lâminas delgadas de diferentes níveis de arenitos conglomeráticos dos dois furos de sondagem TG-98 e TG-100 (Fig. 4). As lâminas das amostras PI-1, PI-3, PI-6, $\mathrm{PI}-7 \mathrm{a}, \mathrm{PI}-7 \mathrm{~b}, \mathrm{PI}-8$ e PI-10 foram confeccionadas no Laboratório de Preparação de Amostras do Centro de Pesquisas em Petrologia e Geoquímica (CPGq) do Instituto de Geociências da UFRGS. A descrição das lâminas e as fotomicrografias foram feitas em um microscópio petrográfico modelo Leica X-7000. Para classificar e avaliar a proveniência das amostras dentro do contexto tectônico proposto pelo método Gazzi \& Dickinson (Dickinson, 1985) foi realizada a contagem modal dos componentes a partir de 600 pontos por amostra (Weltje, 2002). As amostras analisadas foram classificadas no diagrama de Folk (1974). As análises modais foram feitas em microscópio da marca Meiji Techno modelo ML9720. A contagem de pontos foi realizada com auxílio do software PETROLEG. Para avaliar a proveniência dos arenitos, a moda composicional petrográfica foi tratada como a moda mineralógica somada a informações sobre a composição e textura dos 


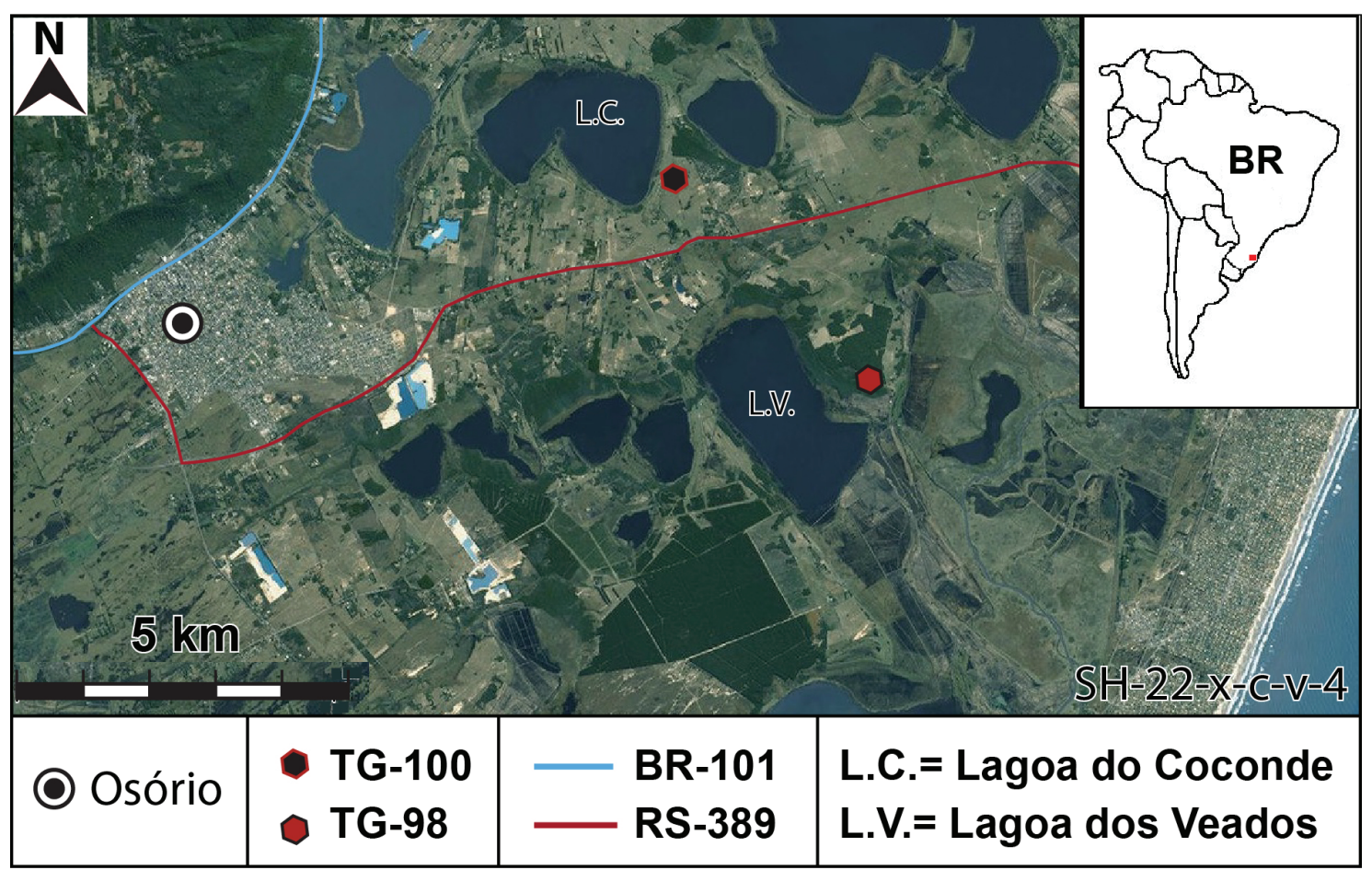

Figura 3. Localização dos furos de sondagem amostrados para as análises petrográficas em imagem de satélite obtida pelo Google Earth Pro (2016).

Figure 3. Location of the sampled drill holes for the petrographic analyzes in the satellite image obtained by Google Earth Pro (2016).

grãos policristalinos, que fornecem a relação direta com as assembléias de rocha da área fonte (Weltje, 2002).

O método Gazzi-Dickinson é uma técnica quantitativa da composição total por contagem de pontos utilizada para medir estatisticamente os componentes de uma rocha sedimentar, principalmente arenito. Este método enfatiza o uso de técnicas petrográficas para reconstruir - contexto tectônico da bacia sedimentar (Dickinson, 1985; Weltje, 2002). Weltje (2002) ressalta, entretanto, que a base estatística teórica do processamento dos dados composicionais em diagramas ternários de (sub) composições restritas a quartzo, feldspato e líticos gera uma limitação estatística, tornando a análise semiquantitativa. A apreciação petrográfica para fins de correlação com ambientes tectônicos específicos é o primeiro método da análise de proveniência dos litotipos de interesse. O foco principal para a técnica está na contagem de todos os componentes do tamanho de areia como grãos separados, independentemente do modo que eles estão conectados. Esta contagem é convertida em percentagens para comparar a composição em estudos de proveniência. A contagem de pontos Gazzi-Dickinson é utilizada em diagramas ternários, como o diagrama QFL, que diferencia os ambientes geotectônicos deposicionais. Os índices dos diagramas são representados por Qt, Qm, F e L. O índice Qt ou quartzo total representa os grãos de quartzo macrocristalino mono ou policristalinos, isolados ou dentro de fragmentos de rochas plutônicas, sedimentares ou metamórficas, ou seja, Qt = Qm + Qp. O índice Qm ou quartzo macrocristalino, corresponde a fragmentos com tamanhos superiores a 0,06 mm, monocristalino ou policristalino grosso. O índice ap ou quartzo policristalino fino é representado por grãos com tamanho inferior a 0,06 $\mathrm{mm}$, de origem sedimentar (chert) ou rochas metamórficas de baixo grau. $\mathrm{O}$ índice $\mathrm{F}$ representa os grãos de K-feldspato e plagioclásio isolados dentro de fragmentos de rochas e com tamanhos superiores a 0,06 mm. 0 índice $L$ é representado por fragmentos de rochas vulcânicas e hipabissais (Lv) e por fragmentos de rochas sedimentares e metamórficas (Ls), compostos por cristais ou grãos com tamanhos inferiores a 0,06 mm. O índice Lt representa o total de litoclastos representados por L+Qp. 


\section{Resultados}

A sucessão descrita nos furos de sondagem é caracterizada por ciclos granodecrescentes constituídos por arenitos conglomeráticos e conglomerados arenosos clasto-suportados e polimíticos com grânulos e seixos de variadas litologias, que sucedem para pacotes de arenitos médios a grossos com estratificação cruzada tangencial e cruzada de baixo ângulo, finalizando em arenitos com marcas de ondas e pelitos laminados no topo (Espíndola, 2017) (Fig. 4).

\section{1 Petrografia}

As sete amostras analisadas dos furos TG-98 e TG-100 correspondem a arenitos conglomeráticos. No diagrama QFL de Folk (1974) as amostras $\mathrm{PI}-1, \mathrm{PI}-7 \mathrm{~b}$ e $\mathrm{PI}-10$ são classificadas como arcóseos, enquanto as amostras PI-3, PI6, Pl-7a e PI-8, como arcóseos líticos (Fig. 5).

Os arenitos e arenitos conglomeráticos tem cor rosa avermelhado e são as rochas dominantes. Os arenitos conglomeráticos apresentam estrutura maciça e são clasto-suportados com grãos que variam de areia fina a areia muito grossa e clastos de tamanho entre grânulo e seixo. A matriz tem baixo grau de seleção e composição à base de quartzo e plagioclásio, com ocorrência subordinada de K-feldspato, minerais opacos e micas. Os grãos de tamanho areia têm formas subangulosas a subarredondadas e baixa esfericidade. O arcabouço é essencialmente clástico. Os litoclastos representam entre $25 \mathrm{e}$ $65 \%$ da rocha. Foram identificados litoclastos de paragnaisses, ortognaisses, metagranitóides miloníticos, metassedimentos de baixo grau, rochas metavulcanoclásticas, xistos magnesianos, muscovita granitos miloníticos, granitos indeformados, rochas sedimentares e rochas vulcânicas, além de intraclastos bacinais de pelitos e siltitos (Fig. 6).

Os clastos de ortognaisses mostram formas subarredondadas a subangulosas. Os gnaisses têm composição tonalítica e apresentam um bandamento irregular $e$ descontínuo, com estrutura milonítica marcada por intensa deformação e recristalização do quartzo, formação de subgrãos em plagioclásio, com deformação de maclas e extinção ondulante.

Associados aos ortognaisses ocorrem clastos demetagranitos, que tambémapresentam formas subarredondadas a subangulosas. A composição varia de tonalítica a granodiorítica, com estrutura foliada e milonítica caracterizada por porfiroclastos estirados de quartzo e de feldspatos. O quartzo forma subgrãos com forte extinção ondulante, com recristalização parcial para agregados granoblásticos finos. Os porfiroclastos de plagioclásio e microclínio apresentam extinção ondulante, maclas deformadas e encurvadas, com formação de subgrãos e recristalização localizada nos bordos para agregados granoblásticos finos.

Os clastos de paragnaisses têm formas alongadas e baixo grau de arredondamento, variando entre silimanita-plágioclásio-cordieritabiotita gnaisses e silimanita-granada-biotita gnaisses. Apresentam um bandamento irregular e descontínuo definido por níveis finos ricos em silimanita do tipo fibrolita, biotita e granada, intercalados com bandas félsicas a base de quartzo, plagioclásio, K-feldspato e cordierita, com textura granoblástica interlobada média $(0,2$ a 0,3 mm). A composição mineral é constituída por quartzo (25-30\%), plagioclásio (15-20\%), biotita (15-20\%), K-feldspato (10-15\%), cordierita (10-15\%), Granada (3-5\%) e silimanita (3-5\%), com magnetita e turmalina subordinadas (Fig. 7). Na figura 7, a fotomicrografia de A e B pertencem a amostra PI-7, C e D à PI-10; E e F à PI-6.

Os metassedimentos de baixo grau incluem quartzitos, xistos pelíticos e mármores, compondo clastos de formas alongadas, subangulosos a subarredondados. Os quartzitos são impuros, com teores entre 4 e 7 $\%$ de muscovita e, magnetita e turmalina como minerais acessórios. A textura é granoblástica interlobada média $(0,15$ a 0,4 mm). Os clastos de muscovita-quartzo xistos e biotita-muscovita xistos tem formas alongadas e subangulosas, comxistosidadeespaçada etextura lepidoblástica média (0,1 a 0,2 mm), intercalando níveis finos ricos em muscovita e biotita e níveis de quartzo, com pouco plagioclásio, microclínio e turmalina (schorlita) (Fig. 8). Na figura 8, a fotomicrografia de $\mathrm{A}$ e $\mathrm{B}$ pertencem a amostra $\mathrm{PI}-8, \mathrm{C}$ e $\mathrm{D}$ à $\mathrm{PI}-1$; 


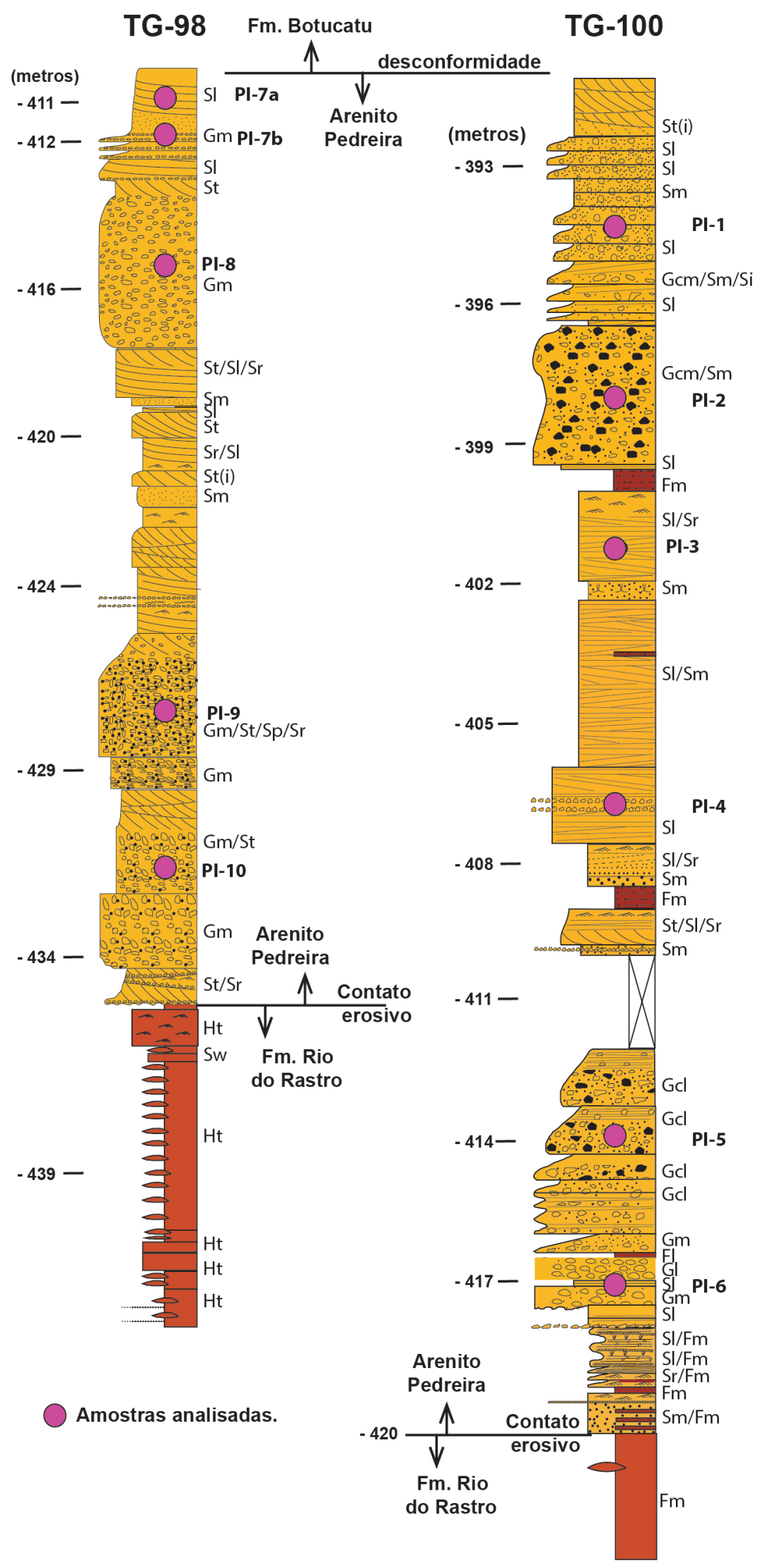

Figura 4. Perfil geológico dos furos de sondagem TG-98 e TG-100, com localização das amostras analisadas (PI-1 a PI10). Fonte: Espíndola (2017).

Figure 4. Geological session of the drilling holes TG-98 and TG-100, with the location of the samples. Source: Espíndola (2017). 


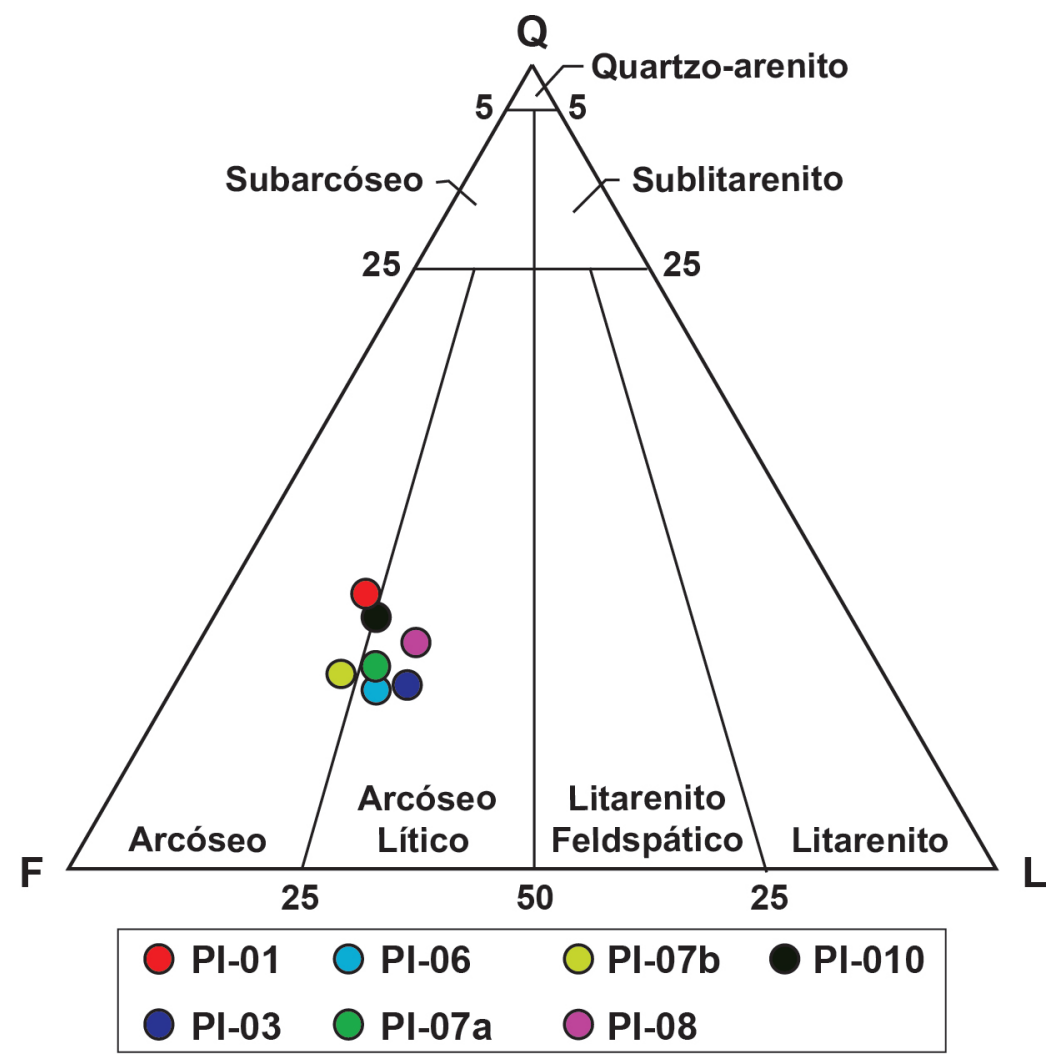

Figura 5. Diagrama de Folk (1974) para classificação das amostras de rochas analisadas. Q: Quartzo, F: Feldspatos e L: Litoclastos.

Figure 5. Folk diagram (1974) for the classification of the analyzed sedimentary rocks. Q: Quartz, F: Feldspar and L: Litoclasts.

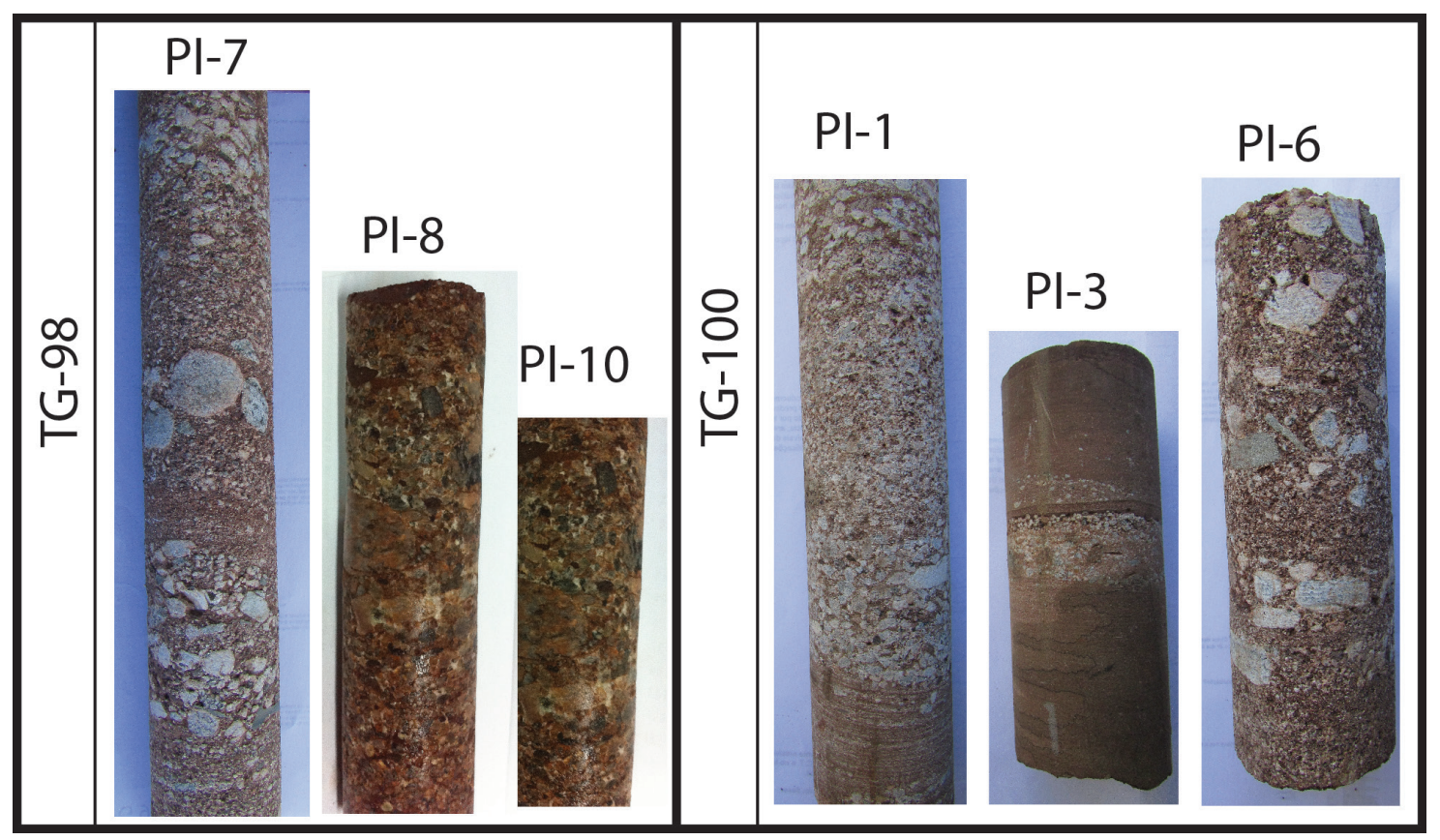

Figura 6. Fragmentos de testemunhos dos furos de sondagem analisados mostrando a variedade de clastos observados nos níveis de arenitos conglomeráticos.

Figure 6. Fragments of the drilling holes analyzed showing the variety of clasts observed in the conglomeratic sandstone levels. 

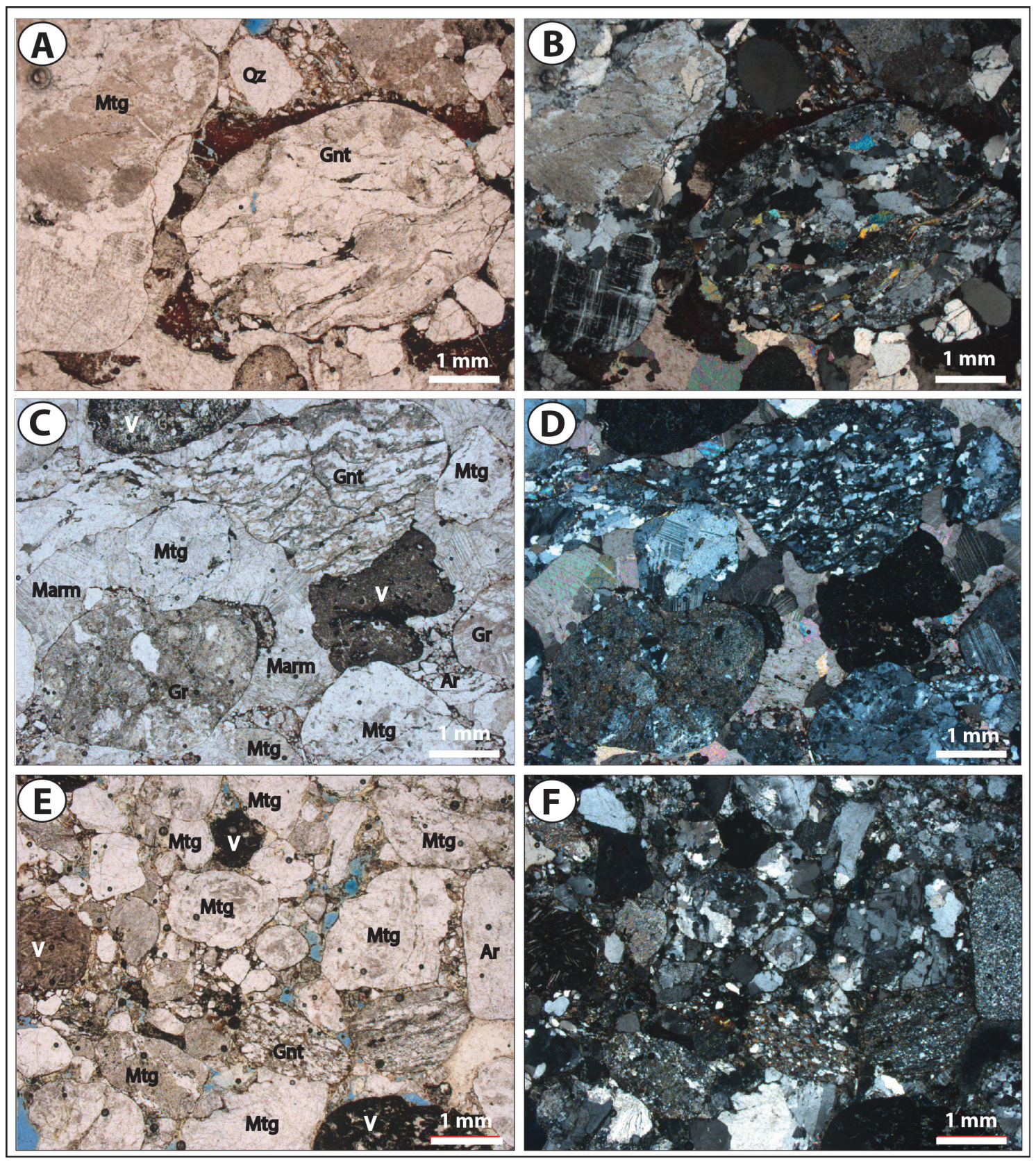

Figura 7. Fotomicrografias dos arenitos conglomerático destacando os litoclastos de gnaisses tonalíticos (Gnt), metagranitos (Mgt), granitos (Gr), basaltos (V), arenitos (Ar) e quartzo (Qz). Fotos A, C e E, luz polarizada, e fotos B, D e F, com polarizadores cruzados.

Figure 7. Photomicrographs of the conglomeratic sandstones highlighting the lithoclasts of tonalitic gneisses (Gnt), metagranites (Mgt), granites (Gr), basalts (V), sandstones (Ar) and quartz (Qz). Photos A, C and E, polarized light, and photos $B, D$ and $F$, with crossed polarizers. 

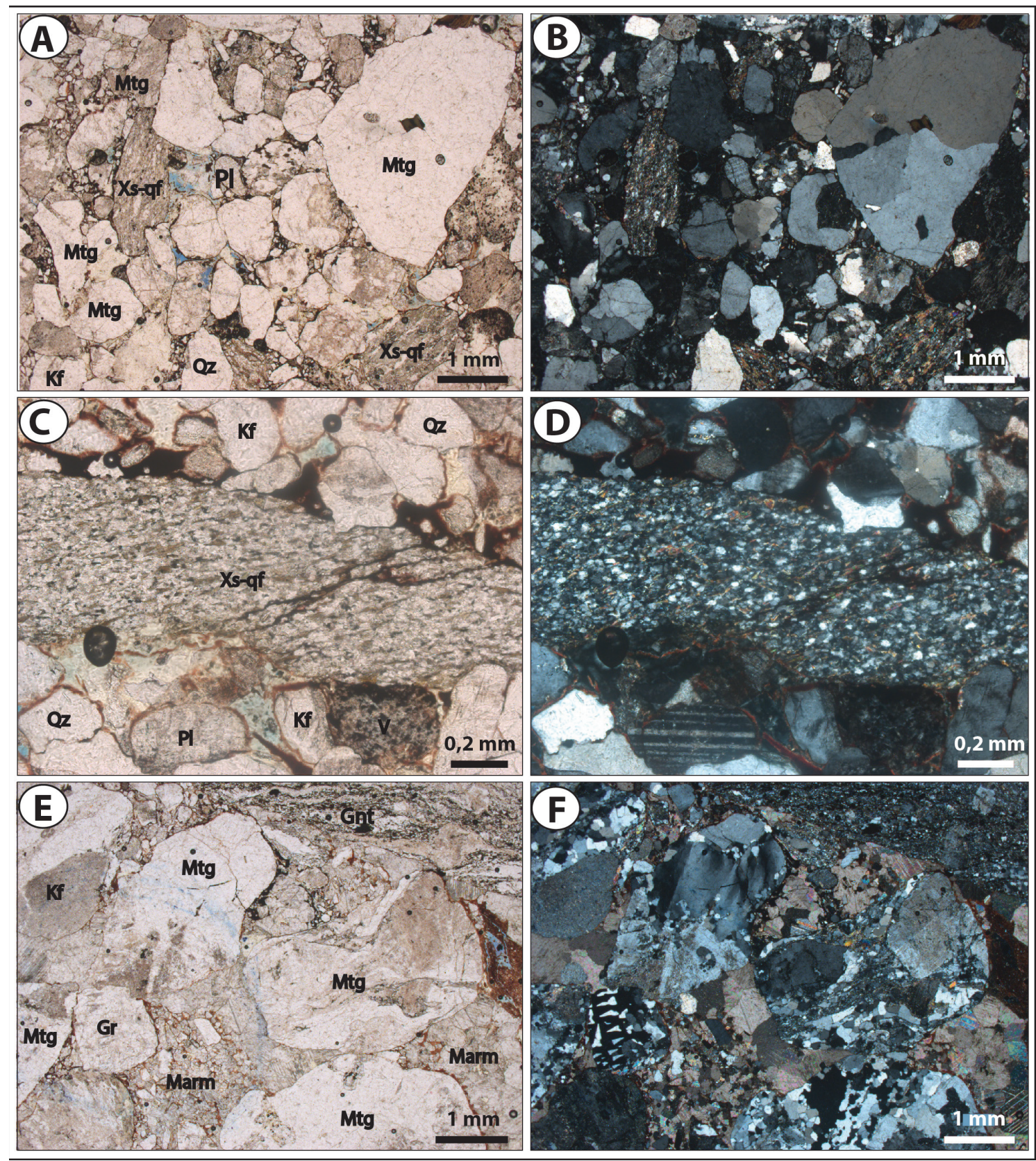

Figura 8. Fotomicrografias dos arenitos conglomeráticos destacando os litoclastos de gnaisses tonalíticos (Gnt), metagranitos (Mtg), xistos quartzo-feldspáticos (Xs-qf), mármores (Marm), granitos (Gr) e basaltos (V), e grãos de plagioclásio (PI-I), K-feldspato (Kf) e quartzo (Qz). Fotos $\mathrm{A}, \mathrm{C}$ e $\mathrm{E}$, luz polarizada, e fotos $\mathrm{B}$, D e $\mathrm{F}$, com polarizadores cruzados.

Figure 8. Photomicrographs of the conglomeratics sandstones highlighting the lithoclasts of tonalitic gneisses (Gnt), metagranites (Mgt), qz-feldspar schists (Xs-qf), marbles (Marm), granites (Gr), basalts (V), and grains of plagioclase (Pl), $K$-feldspar (Kf) and quartz (Qz). Photos A, $C$ and $E$, polarized light, and photos $B, D$ and $F$, with crossed polarizers. 
E e F à PI-10.

Os clastos de rochas metavulcanoclásticas incluem turmalina-plágioclásio-muscovitabiotita-quartzo filitos, com uma clivagem ardosiana caracterizada pela orientação de agregados de biotita verde e/ou muscovita, constituindo a textura lepidoblástica média $(0,1$ a 0,2 mm). A textura porfiroclástica é definida por clastos angulosos e subédricos de quartzo hexagonal e cristais prismáticos alongados de plagioclásio. Também são observados clastos de muscovita-biotita-quartzo-epidoto-clorita xistos com estrutura xistosa definida por uma textura lepidoblástica média a grossa (0,3 a 0,8 mm, até $1,2 \mathrm{~mm})$.

As rochas metaultramáficas ocorrem como clastos de formas equidimensionais e subarredondados, representadas por magnetitaclorita xistos. A xistosidade é definida pela orientação de clorita magnesiana (clinocloro) disposta em textura lepidoblástica média (0,2 a 0,3 mm), com porfiroblastos octaédricos de magnetita. A composição mineral é clorita (98\%) e magnetita (2\%).

Os granitos peraluminosos são representados por clastos de muscovitabiotita monzogranitos com textura equigranular hipidiomórfica média (2 a $5 \mathrm{~mm}$ ). Apresentam formas alongadas e equidimensionais, subangulosas a subarredondadas. A estrutura é foliada, definida pela orientação das micas. A mineralogia é composta por quartzo (25$30 \%)$, plagioclásio (20-25\%), microclínio (1520\%), muscovita (15-20\%) e biotita (3-5\%), com magnetita e turmalina como minerais acessórios. Também foram descritos termos com estrutura protomilonítica caracterizada pelo estiramento do quartzo, com formação de subgrãos e recristalização parcial, com deformação de porfiroclastos de plagioclásio e microclínio e muscovita fish (Figs. 9C e 9D).

Os granitos indeformados constituem sienogranitos com textura equigranular fina a média, compostos por quartzo (35-40\%), K-feldspato (45-50\%), plagioclásio (5-7\%), biotita (3-5\%), muscovita (2-3\%) e magnetita como mineral acessório. Os clastos têm formas circulares a elípticas e são arredondados a subarredondados (Fig. 9E e 9F). Na figura 9, a fotomicrografia de A e B pertencem a amostra $\mathrm{PI}-7 \mathrm{a}, \mathrm{C}$ e D à PI-8; E e F à PI-7b.

As rochas sedimentares estão representadas por intraclastos de pelitos de cor avermelhada. Apresentam formas alongadas e subangulosas, estrutura maciça e composição a base de micas, com pouco quartzo e cimento de óxido de ferro. Também foram descritos clastos de arenitos arcoseanos finos a médios, ricos em quartzo e feldspato, com formas pouco alongadas, subangulosas a subarredondadas.

Os clastos de rochas vulcânicas apresentam composição andesítica ou basáltica, com formas alongadas, subangulosas a subarredondadas. A estrutura é maciça, com texturas afírica e porfirítica definida por 15 a 20\% de fenocristais de 0,1 e 0,2 mm de plagioclásio ripiformes com textura do tipo cauda de andorinha, imersos em matriz vítrea muito oxidada (Fig. 10). Na figura 11, a fotomicrografia de A e B pertencem a amostra $\mathrm{PI}-1, \mathrm{C}$ e D à PI-6; E e F à PI-7b.

\subsection{Diagênese}

As amostras apresentam um elevado grau de compactação mecânica e empacotamento da trama. Os grãos e os litoclastos constituintes apresentam uma relação de contato direto com pouca porosidade primária. Observa-se um registro evolutivo das condições de diagênese em todas as amostras. Os grãos constituintes estão envoltos por uma fina cutícula de hematita bem visíveis na figura 11 E e F. Observa-se também o preenchimento de espaços intersticiais entre os grãos de areia na matriz por franjas de esmectitas. Na lâmina PI-7a observa-se a formação de calcita microcristalina, caracterizada por agregados irregulares de carbonato preenchendo a matriz (Fig. 11 A e B). Na lâmina PI-10 ocorrem franjas de carbonato envolvendo os grãos de feldspato e quartzo da matriz. A evolução desta sequência esta marcada pela deposição de franjas de hematita nos espaços intersticiais finais (Fig. 11 C e D).

Foram ainda registradas feições de compactação química, ocorrendo dissolução por pressão nos contatos de grãos de quartzo e crescimento de quartzo diagenético na forma de uma fina franja de quartzo, visível conforme o 

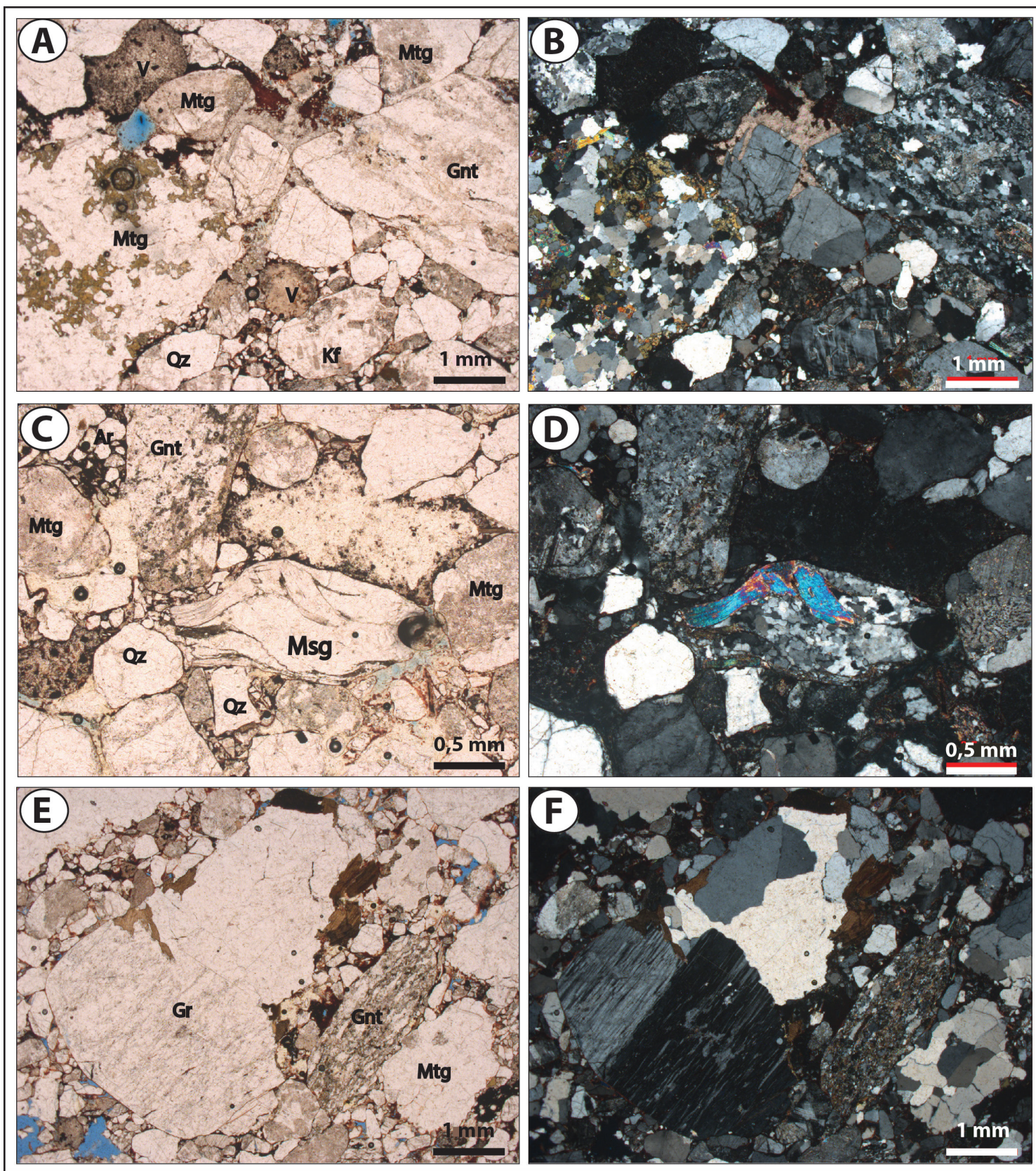

Figura 9. Fotomicrografias dos arenitos com destaque para litoclastos de gnaisses tonalíticos (Gnt), metagranitos (Mtg), muscovita granitos (Musc-gr), granitos (Gr) e basaltos (V), com grãos de K-feldspato (Kf) e quartzo (Qz). Fotos A, C e E, luz polarizada, e fotos $\mathrm{B}$, D e F, com polarizadores cruzados.

Figure 9. Photomicrographs of the sandstones highlighting the lithoclasts of tonalitic gneisses (Gnt), metagranites (Mgt), muscovite granites (Musc-gr), granites (Gr), basalts ( $V$ ), and grains of $K$-feldspar (Kf) and quartz (Qz). Photos A, C and E, polarized light, and photos $B, D$ and $F$, with crossed polarizers. 

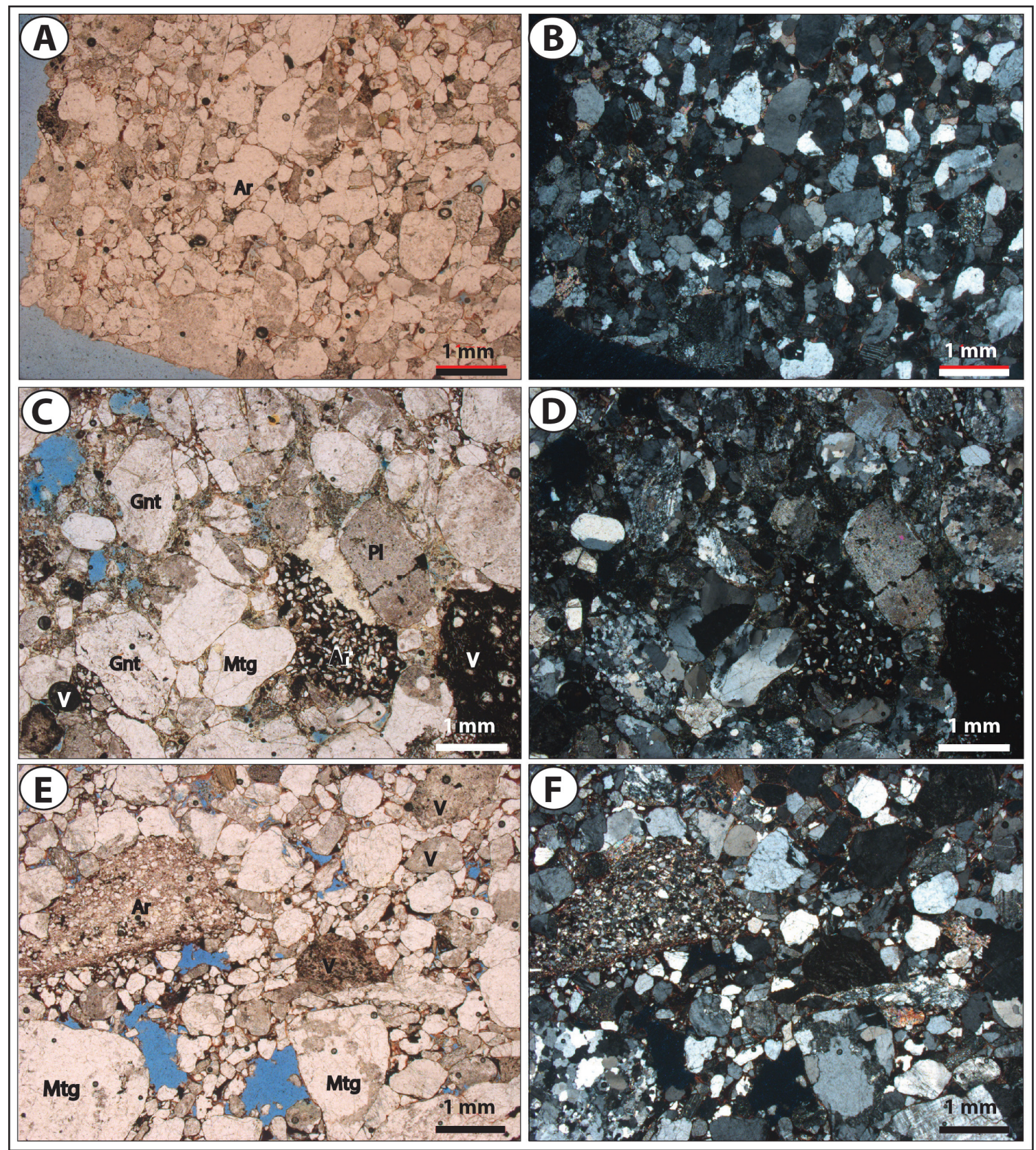

Figura 10. Fotomicrografias dos arenitos conglomeráticos destacando os litoclastos de gnaisses tonalíticos (Gnt), metagranitos (Mtg), arenitos ( $\mathrm{Ar}$ ) e basaltos $(\mathrm{V})$. Fotos $\mathrm{A}, \mathrm{C}$ e $\mathrm{E}$, luz polarizada, e fotos $\mathrm{B}$, D e F, com polarizadores cruzados.

Figure 10. Photomicrographs of the conglomeratics sandstones highlighting the lithoclasts of tonalitic gneisses (Gnt), metagranites (Mgt), arenites (Ar) and basalts ( $V)$. Photos $A, C$ and $E$, polarized light, and photos $B, D$ and $F$, with crossed polarizers. 
ângulo de extinção das bordas de crescimento, distintas do grão principal (Fig. 11 E e F). Também ocorre albitização de feldspatos como produto de alteração diagenética e formação de ilita fibrosa como resultado de alteração principalmente de litoclastos vulcânicos demarcando o processo de mesodiagênese (Fig. 11E e F).

As feições diagenéticas observadasindicam que durante a deposição e a compactação, os arenitos conglomeráticos descritos atingiram condições de soterramento de eodiagênese e mesodiagênese, ocorrendo em condições de clima seco (Worden \& Burley, 2003). A sequência de feições desenvolvidas pode ser observada na figura 12.

\subsection{Proveniência petrográfica}

As sete amostras selecionadas para a contagem modal para determinação da proveniência através do método de GazziDickinson estão representadas nas figuras 13 e 14. De acordo com a classificação Qt$\mathrm{F}-\mathrm{L}$, os arenitos analisados apresentam uma proveniência de arco magmático dissecado. $\mathrm{Na}$ classificação Qm-F-Lt as amostras ocupam o campo de arco magmático com fonte mista, indicando uma importante contribuição de quartzo macrocristalino.

\section{Discussões}

\subsection{Posicionamento estratigráfico}

As evidências de campo obtidas na região de São Leopoldo por Nowatzki \& Kern (2000) e Nowatzki \& Klein (2001) indicam que o Arenito Pedreira apresenta uma sucessão sedimentar muito semelhante a descrita nos furos de sondagem. Desta forma, os dados disponíveis sugerem que a deposição da sucessão analisada ocorreu no intervalo entre a porção intermediária do Triássico e o fim do Jurássico. Assim esta unidade poderia ser correlacionada com as rochas das formações Sanga do Cabral, Santa Maria e Caturrita (Faccini, 2000), do Grupo Rosário do Sul e/ou com as rochas da Formação Guará (Scherer, 2000), do Grupo São Bento. Estas unidades registraram o contínuo processo de continentalização da Bacia do Paraná e se caracterizam pela cor rosa a avermelhada e pela aparente semelhança entre as suas litologias. Para correlacionar a sucessão estudada (Arenito Pedreira) com as unidades deste amplo período foram avaliados elementos como sucessão e arquitetura de fácies, variações de litofácies, sistemas deposicionais e fósseis.

A continentalização da Bacia do Paraná ocorreu a partir do Permiano Superior e ficou registrada nos depósitos continentais da Formação Rio do Rasto e/ou na base do Grupo Rosário do Sul (Formação Sanga do Cabral), caracterizada por depósitos lacustres na base e por um sistema eólico com interdunas úmidas e planícies de canais entrelaçados. Estes depósitos se estenderam portodo o Triássico, representados pelas formações Santa Maria e Caturrita, e foram sucedidos no fim do Jurássico pela deposição das formações Guará e Botucatu. Durante o Triássico o sistema deposicional se caracterizou por um sistema fluvial de canais estáveis a sinuosos, mudando para canais meandrantes no topo com associações de fácies de planície aluviais, com planícies de inundação, depósitos de crevasse e fácies lacustres contendo expressiva ocorrência de fósseis de vertebrados (Faccini, 2000; Schultz et al., 2000). O Jurássico Superior esteve marcado pela passagem de um sistema eólico úmido representado pela Formação Guará, para um amplo sistema eólico seco da Formação Botucatu, cuja deposição é contemporânea com as rochas vulcânicas básicas da Formação Serra Geral, que posteriormente recobrem quase todo este sistema desértico.

A Formação Sanga do Cabral é a unidade basal do Grupo Rosário do Sul, sendo constituída por fácies lacustres, deltaicas, fluviais e eólicas, genética e espacialmente associadas. É composta por arcóseos e litarenitos médios a finos, de cor avermelhada, dispostos como camadas tabulares ou na forma de lentes alongadas, com estratificação plano-paralela, cruzada de baixo ângulo ou acanalada de pequeno a médio porte. Na sua porção basal, apresenta ocorrências subordinadas de arenitos grossos e conglomerados intraformacionais, estes com fragmentos milimétricos a centimétricos de vertebrados fósseis, incluindo anfíbios e 

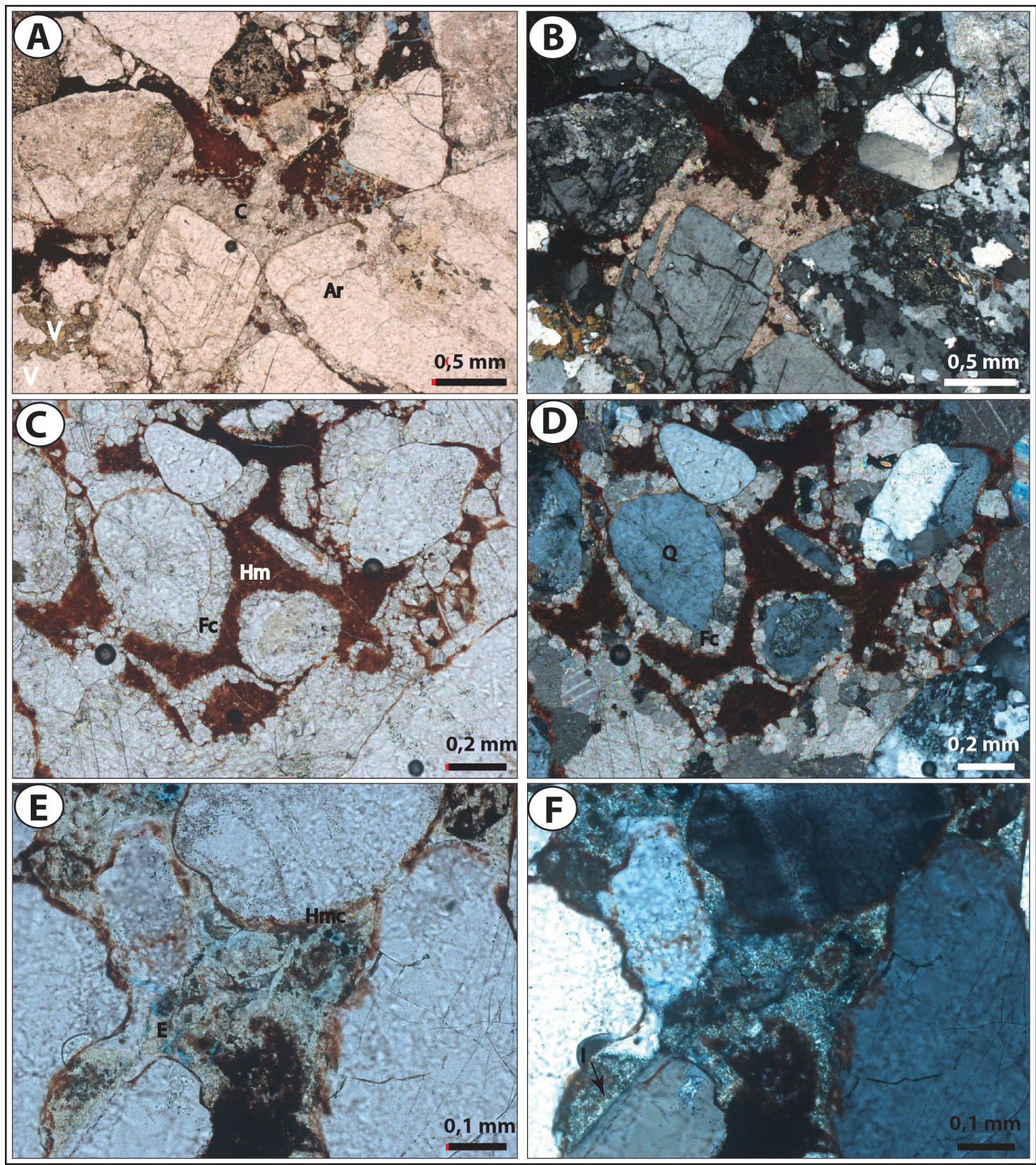

Figura 11. Feições microscópicas da atuação da diagênese. Fotos $A, C$ e E, luz polarizada; fotos B, D e F, polarizadores cruzados. Principais feições diagenéticas descritas: $\mathrm{Fc}=$ franja de carbonato, $\mathrm{Hm}=$ hematita, $\mathrm{C}=$ calcita diagenética, $\mathrm{E}=$ esmectita e $\mathrm{Hmc}=$ cutículas de hematita. $\mathrm{Ar}=$ litoclasto de arenito. $\mathrm{Q}=$ cristal de quartzo e I = llita fobrosa

Figure 11. Microscopic features of the action of diagenesis. Photos A, C and E, polarized light; Photos B, D and F, cross polarizers. Main diagenetic features described: $\mathrm{Fc}=$ carbonate fringe, $\mathrm{Hm}=$ hematite, $\mathrm{C}=$ diagenetic calcite, $E=$ smectite and $\mathrm{Hmc}=$ hematite cucticles. Ar = litoclast of arenite and $Q=$ quartz cristal and $I=$ fibrosis ilite. 


\begin{tabular}{|l|r|r|}
\hline \multicolumn{1}{|c|}{$\begin{array}{c}\text { Estágios diagenéticos/ } \\
\text { Processos }\end{array}$} & Eodiagênese & Mesodiagênese \\
\hline Hematita & - & \\
Esmectita & - & \\
Pirita & & \\
Compactação mecânica & & - \\
Calcita & & - \\
Compactação química \\
Crescimento de quartzo \\
Albita
\end{tabular}

Figura 12. Sequência dos processos diagenéticos observados (o tamanho das barras indica a intensidade dos processos). Figure 12. Sequence of the diagenetic processes observed. The size of the bars indicates the intensity of the processes.

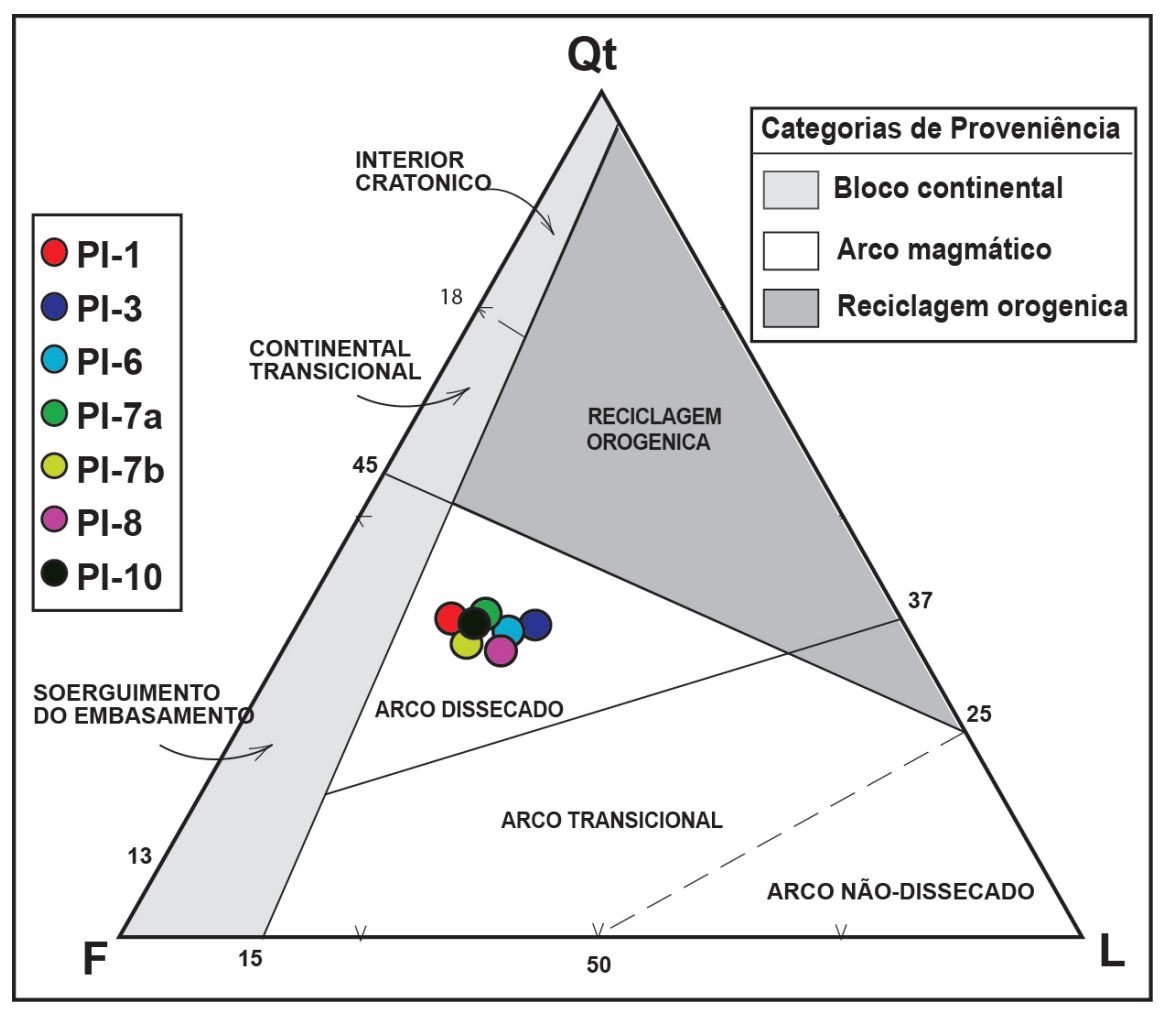

Figura 13. Diagrama de proveniência sedimentar de Gazzi-Dickinson. A) Representação das amostras analisadas no diagrama Qt-F-L para proveniência tectônica; B) Campos representativos dos ambientes geotectônicos.

Figure 13. Gazzi-Dickinson sedimentary provenance diagram. A) Representation of analyzed samples in the Qt-F-L diagram for tectonic provenance. B) Representative fields of the geotectonic environments. 
répteis (Faccini, 2000). Ocorrem raros níveis de ortoconglomerados polimíticos, com arcabouço formado por grânulos e seixos (diâmetro de até $5 \mathrm{~cm}$ ) de rochas ígneas e metamórficas (Faccini, 2000). A idade de deposição é atribuída ao início do Triássico (Série Induana, Olenekiana), definida pela ocorrência de vertebrados fósseis (Barberena et al., 1985). Estes depósitos foram produzidos por fluxos fluviais efêmeros, pobremente canalizados e relacionados a planícies de canais entrelaçados. A base desta formação apresenta um contato transicional com a Formação Rio do Rasto, e na sua porção de topo é delimitada por superfícies erosivas (desconformidades) associadas a deposição dos arenitos fluviais da Formação Santa Maria (Faccini, 2000).

A Formação Santa Maria é subdividida em dois membros. O Membro Passo das Tropas, na sua porção basal, é constituído pela alternância de arenitos e arenitos conglomeráticos de cor rosa avermelhado, com ocorrência subordinada de fácies pelíticas contendo elementos da flora Dicroidium. O Membro Alemoa na sua porção mais superior é composto por siltitos argilosos vermelhos contendo rica fauna de tetrápodos fósseis de idade Meso-Neotriássica (Ladiniano-Carniano) (Barberena et al., 1985; Schultz et al., 2000). O Membro Passo das Tropas está representado por depósitos de canais fluviais de moderada sinuosidade, com níveis restritos de arenitos conglomeráticos intraformacionais, caracterizados por clastos de pelitos avermelhados, raros arenitos e veios de quartzo. O Membro Alemoa é constituído por fácies lacustres e de planícies de inundação.

A Formação Caturrita constitui a unidade de topo do Grupo Rosário do Sul (Faccini, 2000). É composta por arenitos, conglomerados intraformacionais, siltitos arenosos e raros folhelhos, de cores rosa claro a avermelhado. Os depósitos são dominantemente fluviais, associados a fácies de rompimento de diques marginais e deltas lacustres. A ocorrência de vertebrados fósseis permitiu definir a idade de deposição como Neotriássica, entre o Carniano e o Noriano (Barberena et al., 1985; Schultz et al., 2000). O Arenito Mata foi denominado por Faccini (2000) para diferenciá-lo dos depósitos

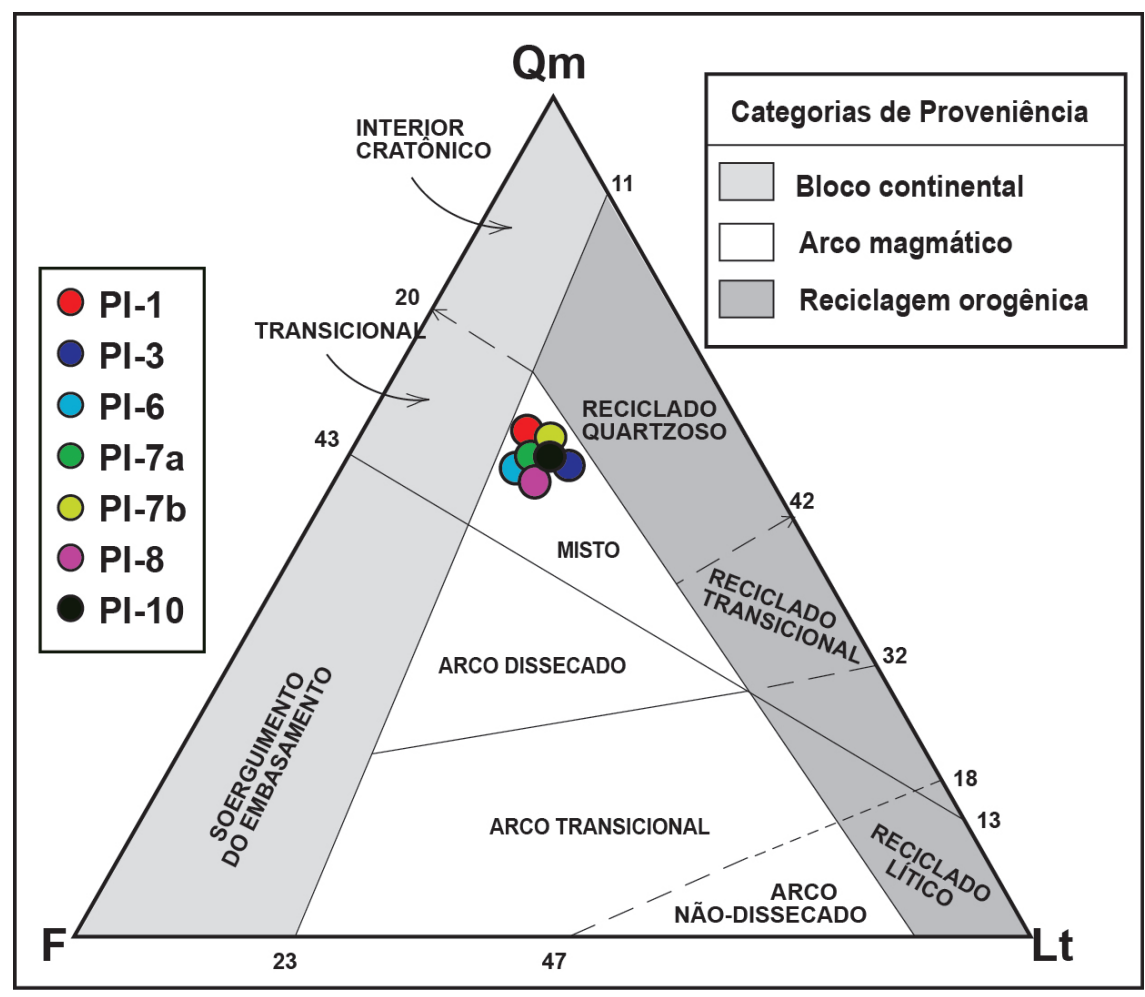

Figura 14. Diagrama de proveniência sedimentar de Gazzi-Dickinson. A) Representação das amostras analisadas no diagrama Qm-F-Lt para proveniência tectônica; B) Campos representativos dos ambientes geotectônicos.

Figure 14. Gazzi-Dickinson sedimentary provenance diagram . A) Representation of analyzed samples in the Qm-F-Lt diagram for tectonic provenance; $B$ ) Representative fields of the geotectonic environments. 
que ocorrem no topo da Formação Caturrita. Os arenitos têm cor rosa claro e composição arcoseana, caracterizados por depósitos fluviais portadores de expressivas acumulações de troncos fósseis de coníferas. Nesta unidade também são descritos níveis restritos de arenitos conglomerático e conglomerados intraformacionais com clastos de pelitos avermelhados.

O Grupo São Bento é composto na sua base pela Formação Guará (Jurássico Superior), sotoposta à Formação Botucatu (Cretáceo) e às lavas da Formação Serra Geral. A Formação Guará foi caracterizada por Scherer \& Lavina (2006) como uma sucessão continental de 80 a $120 \mathrm{~m}$ de espessura que se desenvolveu na porção oeste do estado do RS. Na sua porção norte, é caracterizada por arenitos grossos a conglomeráticos com estrutura em calha e estratificação cruzada planar, bem como laminação de baixo ângulo, que são interpretados para representar depósitos de rios trançados (Scherer \& Lavina, 2006). Os conglomerados estão compostos por seixos de rochas metamórficas e graníticas. Ao Sul, essas fácies fluviais afınam e se entrelaçam com arenitos de grãos finos a médios com estratificação cruzada em grande escala e laminação horizontal, interpretadas como depósitos de dunas eólicas e de areia eólica, respectivamente. O contato entre as formações Guará e Botucatu é delineado por uma superfície de deflação observada em toda a bacia. A mudança abrupta nas condições de deposição que ocorreram através desta supersuperfície sugere uma grande mudança climática, de condições semi-áridas (Jurássico Superior) para condições hiper-áridas (Cretáceo Inferior). A relação entre os depósitos fluviais, eólicos e lacustres sugere que esta formação represente um sistema deposicional desértico (Scherer \& Lavina, 2006). A Formação Botucatu (Cretáceo) caracteriza-se pela formação de grandes estratos transversais formados pela escalada sucessiva de dunas eólicas, sem acumulação interdunitária úmida e/ou fluvial (sistema eólico seco).

As litofácies e os elementos arquiteturais das formações do Grupo Rosário do Sul se caracterizam de modo geral por ocorrências subordinadas de arenitos conglomeráticos e conglomerados. Estes níveis são compostos na sua ampla maioria por conglomerados intraformacionais, caracterizados por litoclastos bacinais, na sua maioria grânulos e seixos de pelitos e arenitos finos. Apesar da composição arcoseana dominada por quartzo e feldspatos, na matriz dos conglomerados são descritos grãos de minerais opacos, granada, estaurolita e outros silicatos de rochas metamórficas e graníticas. Na Formação Sanga do Cabral são descritos litoclastos de veios de quartzo branco, com rara ocorrência de níveis de ortoconglomerados polimíticos, com arcabouço formado por pequenos clastos de rochas ígneas e metamórficas (Faccini, 2000).

A associação de fácies e os elementos arquiteturais descritos nas unidades do Arenito Pedreira são distintos daqueles observados nas unidades do Grupo Rosário do Sul. Desta forma os níveis de arenitos conglomeráticos e conglomerados descritos por Nowatzki \& Kern (2000) e Nowatzki \& Klein (2001) na região de São Leopoldo estão situados abaixo da Fm. Botucatu por desconformidade, e acima das unidades do Grupo Rosário do Sul por uma desconformidade causada por um contato erosivo abrupto. Os autores ressaltam que as unidades do Arenito Pedreira na região de São Leopoldo possuem cerca de $20 \mathrm{~m}$ de espessura, foram geradas em um ambiente de interdunas e apresentam paleocorrente para NW. Enfatizam ainda que a Formação Sanga do Cabral se diferencia em relação ao Arenito Pedreira no seu paleoambiente, na petrografia e nas paleocorrentes, que apresentam direção SW.

As unidades descritas nos furos de sondagem caracterizam uma sucessão de ciclos granodecrescentes compostos por arenitos conglomeráticos e conglomerados arenosos clasto-suportados e polimíticos, sets de arenitos arcoseanos e raros níveis de pelitos. Os arenitos conglomeráticos mostram uma variada tipologia composta por clastos de ortognaisses, metagranitos miloníticos, rochas metamórficas de baixo grau, granitos indeformados, arenitos, pelitos e rochas vulcânicas. Estas unidades foram depositadas entre o Triássico Médio e o Jurássico, visto que se encontram acima da Formação Rio do Rasto e Sanga do Cabral, de 
idade Permiana Superior, e abaixo da Formação Botucatu, de idade Cretáceo inferior.

Nos furos de sondagem o Arenito Pedreira está caracterizado por uma intercalação de dois ciclos de níveis grossos a base de arenitos conglomeráticos e conglomerados com um nível de arenitos finos a médios mais homogêneos. As porções basal e superior dos furos são compostas por níveis de arenitos conglomeráticos e conglomerados clasto suportados, com estrutura maciça e/ou com estratificação cruzada de baixo ângulo, que são interpretados como depósitos associados a um sistema fluvial efêmeros de alta energia. Entre estas fácies fluviais ocorrem arenitos finos a médios com estratificação cruzada de baixo ângulo e tangencial, com porção superior definida por arenitos com laminação cruzada com marcas de ondas e horizontal. Esta porção da sucessão é interpretada como depósitos de dunas e lençóis de areia com sistemas fluviais efêmeros de interdunas.

A sucessão de fácies observada caracteriza uma sedimentação associada a um sistema fluvial arenoso de canais entrelaçados com níveis de conglomerados polimíticos com ampla variedade de litoclastos de rochas ígneas e metamórficas. Estas características permitem sugerir que o Arenito Pedreira poderia ter se depositado de modo contemporâneo com as unidades da Formação Guará, descrita na região de Santana do Livramento e Alegrete por Scherer \& Lavina (2006). A correlação com a base da Formação Santa Maria (Membro Passo das Tropas) fica limitada pela ocorrência dominante de clastos intrabacinais nos níveis de conglomerados desta unidade e pelo ambiente de sedimentação fluvial. Os depósitos do Membro Passo das Tropas representam um sistema fluvial entrelaçado, ao contrário Arenito Pedreira que são interpretados como canais fluviais efêmeros associados a campos de dunas eólicas.

A correlação entre as formações Guará e Botucatu com a seção mesozoica da bacia do Congo (Huab, Namíbia), através das formações Stanleyville e Dekese (Linol et al., 2015), sugere que as unidades do Arenito Pedreira podem corresponder ao Krone Member, considerado com base no seu conteúdo fossilífero, como
Jurássico Superior (Wanke et al., 2000; Linol et al., 2015).

\subsection{Proveniência sedimentar}

Para investigar as rochas fontes e os possíveis caminhos da sucessão sedimentar foram feitas análises petrográficas com análise modal. A quantificação das percentagens dos componentes dos arenitos pode definir assinaturas composicionais dos principais ambientes tectônicos, tais como cráton estável, rifts alimentados pelo soerguimento de blocos do embasamento, arcos magmáticos e cinturões orogênicos com reciclagem de rochas sedimentares, metavulcano-sedimentares, gnaisses e granitóides (Dickinson, 1985). Em alguns casos, as mudanças da sedimentação na bacia podem registrar a história da evolução tectônica do embasamento. Segundo Dickinson (1985), os arcos dissecados apresentam uma mistura de detritos vulcânicos e plutônicos além de clastos metamórficos e sedimentares. Os sedimentos derivados de arcos dissecados também apresentam importante contribuição de K-feldspato e quartzo plutônico juntamente com material vulcanoclástico. A composição dos arenitos é menos vulcano-lítica do que arenitos de arcos não-dissecados (Dickinson \& Suczek, 1979).

Os dados petrográficos dos níveis de arenitos amostrados indicam a presença de litoclastos de rochas metavulcano-sedimentares de baixo grau representadas por xistos micáceos, quartzitos e xistos metavulcanoclásticos; paragnaisses de alto grau; gnaisses tonalíticos a granodioríticos e metagranitóides de grau médio. Ocorrem também xistos ultramáficos (magnetita-clorita xistos), granitos a muscovita com variados graus de milonitização, sienogranitos indeformados, rochas vulcânicas efusivas (andesitos e basaltos), além de pelitos e arenitos. A presença de cristais prismáticos de plagioclásio, zonados e com macla polissintética, de microclínio e quartzo também sustenta uma fonte de rochas plutônicas. As sete amostras selecionadas para a determinação da proveniência através do método de GazziDickinson (Dickinson, 1985) posicionaram-se no 
campo de arco magmático dissecado, sugerindo fontes de arco continental.

O baixo a médio grau de seleção e o baixo arredondamento dos grãos e dos litoclastos em arenitosearenitosconglomeráticos, sugeremárea fonte próxima ao sítio deposicional e transporte relativamente curto. A ocorrência dos mesmos tipos de litoclastos nos níveis amostrados indica que as áreas fontes permaneceram constantes ao longo da deposição dos sedimentos. Os litoclastos de rochas metavulcano-sedimentares de baixo grau e xistos ultramáficos são correlatos com as rochas do Complexo Porongos, ocorrentes na região de Cachoeira do Sul e descritas por Marques et al. (1998), Goldmann et al. (2008), Pertille et al. (2015a, 2015b) e Zvirtes et al. (2017). Os litoclastos de paragnaisses de alto grau, compostos por granada, biotita, silimanita e cordierita são semelhantes aos descritos no Complexo Várzea do Capivarita, na região de Encruzilhada do Sul e Butiá (Silva et al., 2002; Philipp et al. (2013a, 2016). Os gnaisses tonalíticos a granodioríticos e os metagranitoides miloníticos observados são semelhantes as unidades do Complexo Arroio dos Ratos descritas por Martil et al. (2011) e Gregory et al. (2015). A ocorrência de clastos de granitos a muscovita sugere uma relação com os granitos peraluminosos da Suíte Cordilheira descritos na região de Butiá, Arroio dos Ratos e Encruzilhada do Sul por Picada (1969), Nardi \& Frantz (1995), Koster et al. (2001) e Philipp \& Machado (2005). Os clastos de andesitos e basaltos porfiríticos com textura traquítica descritos são similares as rochas vulcânicas da Formação Hilário, do Grupo Bom Jardim, da Bacia do Camaquã, com ampla exposição nas regiões de Cachoeira do Sul (vale do Piquiri), Pântano Grande, Encruzilhada do Sul e Butiá (Paim et al., 2000).

O ambiente deposicional do Arenito Pedreira é interpretado como associado a canais de rios entrelaçados próximos a área fonte devido ao baixo grau de retrabalhamento e seleção. A composição dos litoclastos descritos nos furos de Osório, juntamente com estudos de paleocorrentes apresentados por Nowatzki \& Kern (2000) e Nowatzki \& Klein (2001) para a região de São Leopoldo e Sapucaia do Sul, com direção NE, nos remete a áreas fontes localizadas no Escudo Sul-rio-grandense. As áreas fontes de sedimentos para gerar o Arenito Pedreira estão situadas na porção norte-nordeste do Cinturão Dom Feliciano e correspondem as rochas do embasamento encontradas no Terreno Tijucas e no Batólito Pelotas.

\subsection{Arco de Rio Grande e evolução tectônica da Bacia do Paraná}

As estruturas do embasamento da BP no RS são caracterizadas por sistemas de falhas normais de direção N40-60 E e N40-50'W, representando respectivamente, reativações das antigas zonas de cisalhamento dúcteis e dos principais sistemas de fraturas extensionais (Holz et al., 2006). A evolução da BP envolveu importantes ciclos tectônicos que condicionaram a deposição das sequências sedimentares (Almeida, 1967). Estes ciclos deposicionais estão separados por hiatos temporais que marcam etapas de soerguimento do embasamento e movimentações tectônicas internas na bacia (Milani \& Ramos, 1998; Milani \& Thomaz Filho, 2000; Jelinek et al., 2013, 2014).

Os levantamentos regionais realizados por Milani \& Ramos (1998) concluíram que a estratigrafia da BP está relacionada com a evolução tectônica da porção sudoeste de Gondwana e com a geração do Gondwanides. Os autores demonstraram a relação entre os ciclos de subsidência e os episódios de compressão que afetaram a margem ocidental do antigo continente e levaram a construção da cadeia andina. O preenchimento da bacia está registrado por seis supersequências limitadas por discordâncias regionais, representando os longos períodos de erosão e sedimentação. Cada uma destas supersequências é individualizada por processos de subsidência de natureza variada, recorrentes no tempo e na posição geográfica.

No final do Permiano, após ciclo Gondwânico e o soerguimento dos Gondwanides relacionado as orogêneses Chânica e San Rafaélica, a BP seria confinada ao interior do continente, se isolando do oceano Panthalassa pelo Cinturão do Cabo (Cape Fold belt) / La Ventana (De Wit et al., 1988; Alessandretti et al., 
2013). Durante o Triássico, a porção sudoeste do Gondwana apresentou uma significativa mudança no regime tectônico, de um regime de compressão atuante durante todo o Paleozoico, para um regime distensivo (Zerfass et al., 2003, 2005). Esta importante mudança dos campos de tensão é atribuída ao alívio dos esforços de compressão ativos na margem sul do Gondwana, dando origem a várias bacias distensivas na Argentina e na Bolívia (López-Gamundi et al., 1995; Zerfass et al., 2003).

A integração entre a análise estrutural com a termocronologia por traços de fissão e U-Th-He em apatita, confirmaram a relação proposta por Milani e Ramos (1998) entre os ciclos de deposição da BP e de soerguimento do embasamento, com atividades orogênicas da borda sudoeste de Gondwana (Jelinek et al., 2013, 2014; Philipp et al., 2014). Os dados de termocronologia mostraram que as estruturas do embasamento foram submetidas a vários períodos de reativação durante o Fanerozoico, gerando falhas normais e transcorrentes, muitas vezes com rejeitos da ordem de dezenas a centenas de metros (Philipp et al., 2013b; Jelinek et al., 2014). Os dados apresentados definem quatro eventos tectônicos em escala regional. As idades do Devoniano-Carbonífero (380-340 $\mathrm{Ma}$ ) foram obtidas em unidades do Terreno Taquarembó. Estão associadas a falhas de direção NW-SE e NE-SW e refletem o tectonismo do Evento Famatiniano com a geração de discordância entre as supersequências Rio Ivaí e Rio Paraná (Milani \& Ramos, 1998). No Terreno São Gabriel foram identificadas idades permianas, entre 293-275 Ma e 245-250 Ma, associadas a movimentações das falhas JaguariMata de direção NW-SE. O primeiro grupo caracteriza a discordância entre as sequências Gondwana la e Ib, enquanto o segundo registra o evento orogênico Gondwanides e a formação do Pangea. As idades obtidas no Terreno Tijucas, entre o Triássico Superior e o Jurássico Inferior, indicam as movimentações dos sistemas de falhas regionais de direção NW-SE, como JaguariMata, Ibaré e Alegrete. A porção mais oriental do Batólito Pelotas apresentou idades entre 277 e 200 Ma para falhas normais de direção NE-SW. O setor NE do batólito apresenta idades mais jovens, entre 190 e 150 Ma, que representam principalmente os o início dos ajustes de préderiva das Placas Sul-Americana e Africana (Jelinek et al., 2014).

No estado do RS o registro da sedimentação triássica do Grupo Rosário do Sul marca o início de uma fase de rift que expõe grande parte da área BP gerando uma extensa superfície erosiva. Esta fase coincide com uma mudança no estilo deposicional, com a passagem da Formação Sanga do Cabral para a Formação Santa Maria. A base desta última, caracterizada pelas rochas do Membro Passo das Tropas, é composta por sequências aluviais com arenitos grossos e conglomerados evoluindo para sistemas fluviais entrelaçados. Esta notável incisão fluvial e seus processos de sedimentação estiveram relacionados à redução do nível estratigráfico de base, interpretada como uma resposta sedimentar à reorganização tectônica da bacia (Faccini, 2000, 2007; Zerfass et al., 2003, 2005). Estes eventos representaram a resposta intra-placa de um processo de compressão regional associado com a subducção do oceano Pantalassa contra a margem sul do Gondwana, originando a Sierra de la Ventana ( 260 Ma), na Argentina e o Cape Fold Belt, na África do Sul (De Witt et al., 1988). A estrutura tectônica que condiciona a deposição dos sedimentos triássicos no RS está caracterizada por uma calha principal de direção NW-SE, e cujos dados de paleocorrente para N-NE indicam um soerguimento regional da parte sul do Escudo sul-rio-grandense (Faccini, 2000, 2007).

Este soerguimento é responsável por um arqueamento regional e pela formação do Arco do Rio Grande. A estruturação deste arco esteve ligada a reativação Wealdeniana conforme descrita por Almeida (1967) (Fig. 15). Esta estrutura está limitada ao norte pelo Sistema de Falha Jaguari-Mata e ao sul pelo Sistema de Falhas Ibaré-Alegrete, conforme levantamentos sedimentares apresentados por Faccini (2000), Da Rosa \& Faccini (2005) e Machado (2005), e por levantamentos estruturais, geocronológicos e geofísicos (método magneto-telúrico) sintetizados por Philipp et al. (2013b, 2014).

No início do Jurássico a porção central do Escudo Sul-rio-grandense estava soerguida 


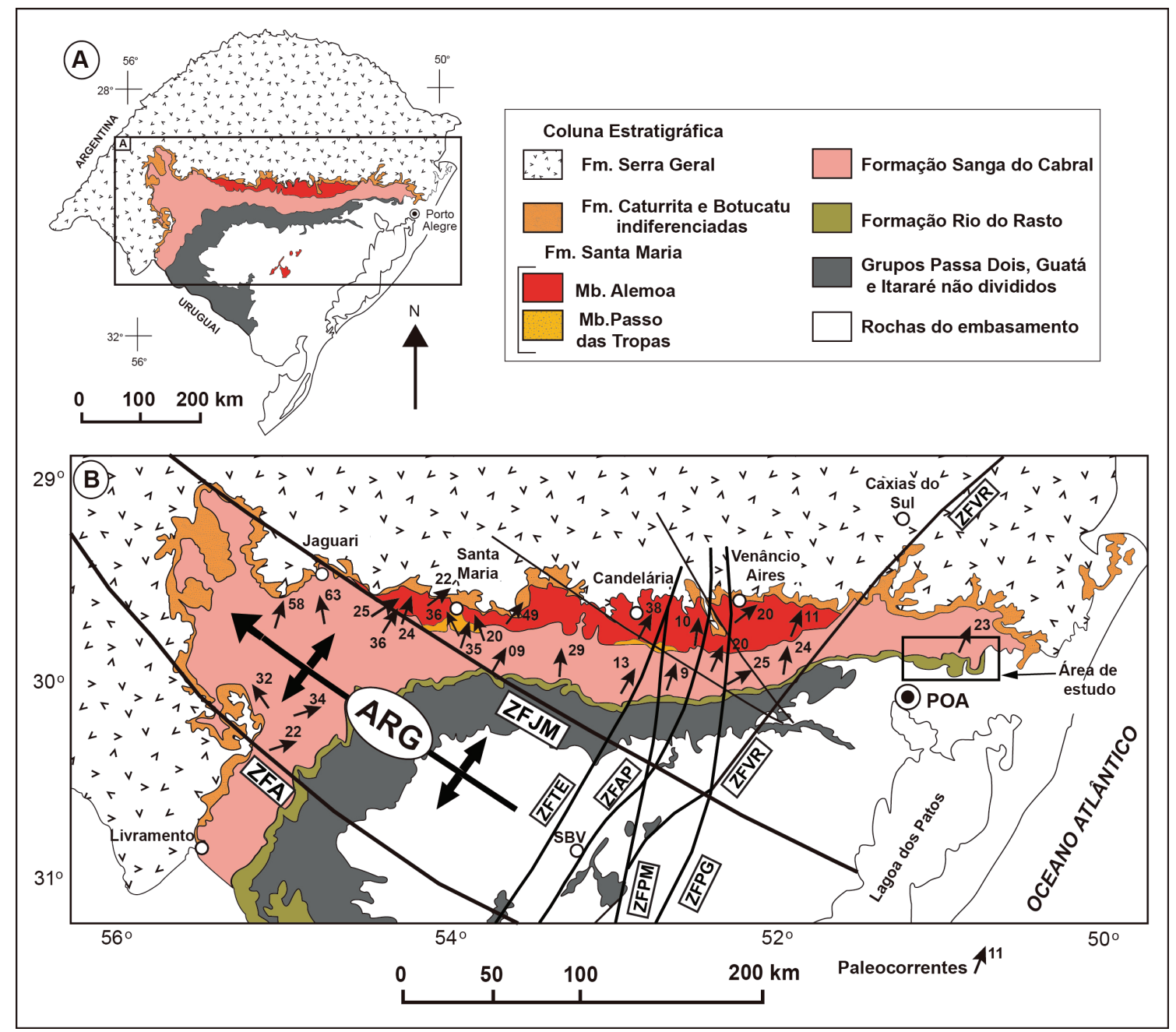

Figura 15. Mapa geológico do Rio Grande do Sul destacando as unidades sedimentares da BP. A) Área de exposição da borda sul da Bacia do Paraná no RS; B) Mapa geológico da BP, destacando os sistemas de falhas que delimitam o Arco do Rio Grande (ARG). ZF = Zonas de falha: JM - Jaguari Mata, A - Alegrete, AP- Acotéia-Piquiri, PM - Passo dos Marinheiros, PG - Pântano Grande, VR - Vigia Roque.

Figure 15. Geological map of Rio Grande do Sul highlighting the sedimentary units of PB. A) Exposure area of the south board of Paraná Basin in the RS State; B) Geological map of the PB, highlighting the fault systems that delimit the Rio Grande Arc (ARG). ZF = Fault Zones: JM - Jaguari Mata, A - Alegrete, AP-Acotéia-Piquiri, PM - Passo dos Marinheiros, PG - Pântano Grande, VR - Vigia Roque.

pelo Arco do Rio Grande e mais a nordeste, rebaixada pela Sinclinal de Torres, ambas estruturas orientadas segundo a direção NW-SE. Este alto topográfico refletiria uma mudança nas condições de sedimentação e no fornecimento de sedimentos para as unidades Jurássicas e Cretáceas na Bacia do Paraná. Neste caso, as fontes da sedimentação que geraram o Arenito Pedreira estariam situadas mais ao S-SW, confirmadas pelas paleocorrentes para N-NE determinadas por Nowatzki \& Kern (2000) e Nowatzki \& Klein (2001). Esta hipótese é confirmada pela natureza dos litoclastos identificados nos níveis de arenitos conglomeráticos e conglomerados e reforçada pelos resultados dos diagramas Qt-F-L e QmF-Lt propostos por Gazzi-Dickinson (Dickinson, 1985). A fonte dos sedimentos é de um arco magmático continental, representado pelas unidades do Cinturão Dom Feliciano.

Os dados disponíveis permitem supor que no final do Jurássico, o soerguimento do Arco de Rio Grande expôs o embasamento, que serviu de fonte para a deposição de duas sucessões distintas, embora contemporâneas. A Formação Guará, situada ao sudoeste do arco, com paleocorrentes para S-SW e a unidade Arenito Pedreira, situada ao nordeste do arco e com paleocorrentes para N-NE. 


\section{Conclusões}

A unidade denominada de Arenito Pedreira é composta por uma sucessão de ciclos granodecrescentes constituídos por arenitos conglomeráticos e conglomerados arenosos sucedidos para pacotes de arenitos médios a grossos, com estratificação cruzada tangencial e cruzada de baixo ângulo, finalizando em arenitos com marcas de ondas e pelitos laminados no topo. Os conglomerados são clasto-suportados e polimíticos com grânulos e seixos angulosos de rochas metamórficas de baixo e alto graus, ortognaisses e metagranitóides miloníticos, granitos peraluminosos deformados, rochas vulcânicas e sedimentares.

O Arenito Pedreira é uma unidade peculiar dentro da Bacia do Paraná, que registrou um período de atividade tectônica atuante provavelmente durante o fim do Jurássico. A sedimentação ocorreu de forma rápida, causada por rios efêmeros associados ao fim do período de mudanças climáticas causadas pela intensa atividade vulcânica desenvolvida durante o Permo-Triássico. A área fonte é próxima do locus da deposição e se originou a partir da erosão de rochas encontradas no Cinturão Dom Feliciano. Pela posição geográfica dentro da bacia e pelos dados de paleocorrentes podemos sugerir que o Arenito Pedreira é o resultado da erosão das rochas encontradas no Terreno Tijucas e no Batólito Pelotas.

As unidades do Arenito Pedreira e da Formação Guará registram pelo tipo de sucessão sedimentar e pelos dados de paleocorrentes a estruturação do Arco de Rio Grande. A deposição destas unidades é o resultado da erosão do arco, sugerindo que esta estrutura delimitou a sedimentação destas unidades sobre 0 embasamento.

\section{Referências}

Alessandretti, L., Philipp, R.P., Chemale Jr., F., Brückmann, M. P., Zvirtes, G., Matté, V. \& Ramos, V.A. 2013. Provenance, volcanic record, and tectonic setting of the Paleozoic Ventania Fold Belt and the Claromecó Foreland Basin: Implications on sedimentation and volcanism along the southwestern Gondwana margin. Journal of South American Earth Sciences, 47(1): 12-31.

Almeida, F.F.M. 1967. Origem e evolução da plataforma brasileira. DNPM-DGM, Rio de Janeiro, Boletim 241, p. 1-36.

Andreis, R.R., Bossi, G.E. \& Montardo, D.K. 1980. O Grupo Rosário do Sul (Triássico) no Rio Grande do Sul, Brasil. In: CONGRESSO BRASILEIRO DE GEOLOGIA, 31., 1980, Balneário Camburiú. Anais... Balneário Camburiú, SBG, v. 2: 659673.

Barberena, M.C., Araújo, D.C., Lavina, E.L. \& Azevedo, S.A. 1985. O estado atual do conhecimento sobre os tetrápodes permianos e triássicos do Brasil Meridional. Coletânea de Trabalhos Paleontológicos, MME-DNPM, Série Geologia, Seção de Paleontologia, 27(2): 21-28.

Da Rosa, Á.A.S. \& Faccini, U.F. 2005. Delimitação de blocos estruturais de diferentes escalas em seqüências Mesozóicas do Estado do Rio Grande do Sul: implicações bioestratigráficas. Gaea, 1: 16-23.

De Wit, M.J., Jeffery, M., Bergh, H. \& Nicolaysen, L. 1988. Geological map of sectors of Gondwana, reconstructed to their disposition $\sim 150 \mathrm{Ma}$. Tulsa, American Association of Petroleum Geologists/University of Witwatersrand, escala 1:10.000.000.

Dickinson, W.R. 1985. Interpreting provenance relations from detrital modes of sandstones. In: Zuffa. G.G. (Ed.). Provenance of Arenites. Springer, Dordrecht, 148: 333-361.

Dinckinson, W.R. \& Suczek, C.A. 1979. Plate tectonics and sandstone compositions. The American association of Petroleum Geologist Bulletin,63(12): 2164-2182.

Espíndola, E. 2017. Análise arquitetural de depósitos flúvio-eólicos das formações do Jurássico superior - Cretáceo inferior na borda leste da Bacia do Paraná, RS, Brasil. Porto Alegre, 64 p. Dissertação de Mestrado, Programa de Pós-graduação em Geociências, Instituto de Geociências, Universidade Federal do Rio Grande do Sul.

Faccini, U.F. 2000. Estratigrafia do permotriássico do Rio Grande do Sul: estilos deposicionais versus espaço de acomodação. 
Porto Alegre, 332 p. Tese de Doutorado, Programa de Pós-graduação em Geociências, Instituto de Geociências, Universidade Federal do Rio Grande do Sul.

Faccini, U.F. 2007. Mesozoic sedimentary record of Southern Paraná Basin, Brazil. In: I, WORKSHOP - PROBLEMS IN WESTERN GONDWANA GEOLOGY, 2007. Gramado. Extended Abstracts... Gramado, SBG, v.1, p. 42-45.

Folk, R.L. 1974. Petrology of sedimentary rocks. Handbook Hemphill Pub.Co, Austin, Texas, (127 p.).

Goldmann, K., Marques, J.C., Frantz, J.C. \& Chemale Jr., F. 2008. Geoquímica e isótopos de Nd de Rochas metavulcânicas da Antiforme Capané, Complexo metamórfico Porongos, RS. Pesquisas em Geociências, 35(2): 83-95.

Gregory, T.R., Bitencourt, M.A.F.S., Nardi, L.V.S., Florisbal, L.M. \& Chemale Jr., F. 2015. Geochronological data from TTG-type rock associations of the Arroio dos Ratos Complex and implications for crustal evolution of southernmost Brazil in Paleoproterozoic times. Journal of South American Earth Sciences, 57: 49-60.

Holz, M., Kuchle, J., Philipp, R.P., Bischoff, A.P. \& Arima, N. 2006. Hierarchy of tectonic control on stratigraphic signatures: base-level changes during the Early Permian in the Parana', Basin, southernmost Brazil. Journal of South American Earth Sciences, 22: 185-204.

Holz, M., França, A.B., Souza, P.A., lanuzzi, R. \& Rohn, R.A. 2010. A Stratigraphic chart of the Late Carboniferous/Permian sucession of the eastern border of the Paraná Basin, Brazil, South America. Journal of South American Earth Sciences, 29:381-399.

Jelinek, A.R., Philipp, R.P. \& Chemale Jr., F. 2013. Evolução termo-tectônica do Cinturão Dom Feliciano no RS e SC a partir da integração da análise por traços de fissão em apatita e da geologia estrutural. In: SIMPÓSIO NACIONAL DE ESTUDOS TECTÔNICOS, XIV. 2013, Chapada dos Guimarães, Boletim de Resumos Expandidos... Chapada dos Guimarães, SBG, CD-Rom.

Jelinek, A.R., Philipp, R.P., Chemale Jr., F., Faccini, U., Viana, A.R. \& Lavina, E. 2014. The tectonic- thermal history of the Southern Brazillian Shield and the relation to the depositional history of Paraná Basin. In: INTERNATIONAL CONFERENCE OF TERMOCHRONOLOGY, 14., 2014. Chamonix. Abstract Book... Paris, University of Grenoble. v. 1.

Koester, E., Roisemberg, A., Fernandes, L.A.D., Soliani Jr., E., Nardi, L.V.S. \& Kraemer, G. 2001. Petrologia dos granitóides sintectônicos à Zona de Cisalhamento Transcorrente Dorsal de Canguçu, Encruzilhada do Sul, RS. Revista Brasileira de Geociências, 31(2): 131-140.

Linol B., de Wit M.J., Milani, E.J., Guillocheau, F. \& Scherer, C. 2015. Chapter 13: New regional correlations between the Congo, Paraná and Cape-Karoo Basins of southwest Gondwana. In: de Wit MJ, Guillocheau, F, de Wit MJC (eds) The Geology and Resource Potential of the Congo Basin, Regional Geology Reviews. Springer-Verlag, Berlin Heidelberg, 246-268.

López-Gamundi, O.R., Conaghan, P.J., Rosselo, E.A. \& Cobbold, P.R. 1995. The Tunas Formation (Permian in the Sierras Australes Fold belt) east central Argentina: evidence for syntectonic sedimentation in a foreland basin. Journal of South American Earth Sciences, 8: 129-142.

Machado, J.L.F. 2005. Compartimentação espacial e arcabouço hidroestratigráfico do Sistema Aqüífero Guarani no Rio Grande do Sul. São Leopoldo, 237 p. Tese de Doutorado, Programa de Pós-Graduação em Geologia, UNISINOS.

Marques, J.C., Jost, H., Roisemberg, A. \& Frantz, J.C. 1998. Eventos ígneos da Suíte Metamórfica Porongos na área da Antiforme Capané, Cachoeira do Sul, RS. Revista Brasileira de Geociências, 28(4): 419-430.

Martil, M.M.D., Bitencourt, M.F. \& Nardi, L.V.S. 2011. Caracterização estrutural e petrológica do magmatismo pré-colisional do Escudo Sulrio-grandense: os ortognaisses do Complexo Metamórfico Várzea do Capivarita. Pesquisas em Geociências, 38(2): 181-201.

Milani, E.J. 1997. Evolução tectono-estratigráfica da Bacia do Paraná e seu relacionamento com a geodinâmica fanerozóica do Gondwana sul-ocidental. Porto Alegre, 294 p. Tese de Doutorado. Programa de Pós-Graduação 
em Geociências, Instituto de Geociências, Universidade Federal do Rio Grande do Sul.

Milani, E.J. \& Ramos, V.A. 1998. Orogenias

Paleozóicas no domínio sul-ocidental do Gondwana e os ciclos de subsidência da Bacia do Paraná. Revista Brasileira de Geociências, 28: 473-484.

Milani, E.J. \& CThomaz Filho, A. 2000. Sedimentary basins of South America \& Tectonic evolution of South America. In: INTERNATIONAL GEOLOGICAL CONGRESS, 31., 2000, Rio de Janeiro. Anais... v. 1: 389-449.

Milani, E.J., Melo, J.H.G., Souza, P.A., Fernandes, L.A., França, A.B. 2007. A Bacia do Paraná. Boletim de Geociências da Petrobrás, 15(2):265-287.

Nardi, L.V.S. \& J.C. Frantz. 1995. The Cordilheira Intrusive Suite: Late Proterozoic peraluminous granitoids from the southern Brazil. Journal of South American Earth Sciences, 8(1): 55-63.

Nowatzki, C.H. \& Kern, H.P. 2000. The eolianites between Sanga do Cabral and Botucatu formations in Rio Grande do Sul State, Brazil. Anais da Academia Brasileira de Ciências, 72(2): 247-256.

Nowatzki, C.H. \& Klein, C. 2001. A Formação Sanga do Cabral na região de São Leopoldo, Rio Grande do Sul, Brasil. Geologia Colombiana, 26: 45-57.

Paim, P.S.G., Chemale Jr., F. \& Lopes, R.C. 2000. A Bacia do Camaquã. In: Holz, M. \& De Ros, L.F. (Ed.). Geologia do Rio Grande do Sul. CIGO/ UFRGS, Porto Alegre, p. 231-274.

Pertille, J., Hartmann, L.A. \& Philipp, R.P. 2015a. Zircon $\mathrm{U}-\mathrm{Pb}$ age constraints on the Paleoproterozoic sedimentary basement of the Ediacaran Porongos Group, SulRiograndense Shielf, southern Brazil. Journal of South American Earth Sciences, 63: 334345.

Pertille, J., Hartmann, L.A., Philipp, R.P., Petry, T.S. \& Lana, C.C. 2015b. Origin of the Ediacaran Porongos Group, Dom Feliciano Belt, southern Brazilian Shield, with emphasis on whole rock and detrital zircon geochemistry and $\mathrm{U}-\mathrm{Pb}$, Lu-Hf isotopes. Journal of South American Earth Sciences, 64: 69-93.

Philipp, R.P. \& Machado, R. 2005. The Late Neoproterozoic granitoid magmatism of the
Pelotas Batholith, southern Brazil. Journal of South American Earth Sciences. Londres, 19: 461-478.

Philipp R.P., Massone, H.J. \& Campos, R.S. $2013 a$. Peraluminous leucogranites of Cordilheira Suite, record of Neoproterozoic collision and generation of Pelotas Batholith, Dom Feliciano Belt, southern Brazil. Journal of South American Earth Sciences, 43: 8-24.

Philipp, R.P., Zvirtes, G., Brückmann, M.P., Faccini, U.F., Viana, A.R., Lavina, E. \& Scherer, C.M.S. 2013b. Estruturas tectônicas na seção geológica Santana do Livramento-Rosário do Sul-Jaguari: evidências do Arco de Rio Grande, Bacia do Paraná, RS. In: SIMPÓSIO NACIONAL DE ESTUDOS TECTÔNICOS, XIV, Chapada dos Guimarães, Boletim de Resumos Expandidos ... Chapada dos Guimarães, SBG, v. 1. CD-Rom.

Philipp, R.P., Rolim, S.B.A., Malta, L., Jelinek, A.R., Viana, A., Lavina, E.L., Cagliari, J. \& Faccini, U.F. 2014. Estruturação do Arco de Rio Grande e da Sinclinal de Torres, Bacia do Paraná, RS: evidências por levantamentos magnetotelúricos. SIMPÓSIO BRASILEIRO DE GEOFÍSICA, VI, Porto Alegre. Extended Abstracts... Porto Alegre, SBGf, v. 1.

Philipp, R.P., Bom, F.M., Pimentel, M.M., Junges, S.L. \& Zvirtes, G. 2016. SHRIMP U-Pb age and ultra-high temperature conditions of the collisional metamorphism in the Várzea do Capivarita Complex: implications for the origin of Pelotas Batholith, Dom Feliciano belt, southern Brazil. Journal of South American Earth Sciences, 66: 196-207.

Picada, R.S. 1969. Faixadegranitossincinemáticos no Escudo Sul-Riograndense. In: CONGRESSO BRASILEIRO DE GEOLOGIA, 23. 1969, Salvador, Resumo de Comunicações.... Salvador, SBG, v.86.

Scherer, C.M.S. 2000. Eolian dunes of the Botucatu Formation (Cretaceous) in Southernmost Brazil: morphology and origin. Sedimentary Geology, 137: 63-84.

Scherer, C.M.S. \& Lavina, E.L. 2006. Stratigraphic evolution of a fluvial-eolian succession: The example of the Upper Jurassic-Lower Cretaceous Guará and Botucatu formations, Paraná Basin, Southernmost Brazil. Gondwana 
Research, 9: 475-484.

Schultz, C.L., Scherer, C.M.S. \& Barberena, M.C. 2000. Biostratigraphy of Southern Brazilian Middle-Upper Triassic. Revista Brasileira de Geociências, 30(3): 495-498.

Silva, A.O.M., Porcher, C.C., Fernandes, L.A.D. \& Droop, G.T.R. 2002. Termobarometria da Suíte Metamórfica Várzea do Capivarita (RS): Embasamento do Cinturão Dom Feliciano. Revista Brasileira de Geociências, 32: 419432.

Weltje, G.J. 2002. Quantitative analysis of detrital modes: statistically rigorous confidence regions in ternary diagrams and their use in sedimentary petrology. Earth-Science Reviews, 57: 211-253.

Worden, R.H. \& Burley, S.D. 2003. Sandstone diagenesis: the evolution of sand to stone. International Association of Sedimentologists, (4): $44 \mathrm{p}$.

Zerfass, H., Chemale Jr., F., Schultz, C.L. \& Lavina, E. 2003. Tectonics and sedimentation in Southern South America during Triassic. Sedimentary Geology, 166: 265-292.

Zerfass, H., Chemale Jr., F. \& Lavina, E. 2005. Tectonic Control of the Triassic Santa Maria Supersequence of the Paraná Basin, Southernmost Brazil, and its Correlation to the Waterberg Basin, Namibia. Gondwana Research, 8: 163-176.

Zvirtes, G., Philipp, R.P., Camozzato, E. \& Guadagnin, F. 2017. Análise estrutural do Metagranito Capané, Complexo Porongos, Cachoeira do Sul, RS. Pesquisas em Geociências. 44(1): 5-23.

Manuscrito 658 | Recebido em abril de 2017 | Aceito em ago. de 2019 | Editor: César L. Schultz 